This PDF is a selection from an out-of-print volume from the National Bureau of Economic Research

Volume Title: Frontiers in Health Policy Research, volume 1

Volume Author/Editor: Alan M. Garber, editor

Volume Publisher: MIT

Volume ISBN: 0-262-57120-X

Volume URL: http://www.nber.org/books/garb98-1

Publication Date: January 1998

Chapter Title: Managed Care and the Growth of Medical Expenditures

Chapter Author: David M. Cutler, Louise Sheiner

Chapter URL: http://www.nber.org/chapters/c9824

Chapter pages in book: (p. 77 - 116) 


\title{
Managed Care and the Growth of Medical Expenditures
}

\author{
David M. Cutler, Harvard University and National Bureau of \\ Economic Research
}

Louise Sheiner, Federal Reserve Board of Governors

\section{Executive Summary}

We use data across states to examine the relation between HMO enrollment and medical spending. We find that increased managed care enrollment significantly reduces hospital cost growth. Although increased spending on physicians offsets some of this effect, we generally find a significant reduction in total spending as well. In analyzing the sources of hospital cost reductions, we find preliminary evidence that managed care has reduced the diffusion of medical technologies. States with high managed care enrollment were technology leaders in the early 1980 s; by the early 1990 s those states were only average in their acquisition of new technologies. This finding suggests managed care may significantly affect the long-run growth of medical spending.

Over the past few years, health insurance costs have made a dramatic turnaround. After decades of double-digit increases, health insurance cost growth has essentially ground to a halt. Most observers point to managed care as the leading culprit. "The growing dominance of managed care has helped control health care cost increases," the New York Times editorialized. "What this demonstrates is that in the private sector, managed care and competition are lowering the rate of cost increases in health care," Representative Nancy Johnson stated.

But the evidence on this point is far from compelling. Some surveys find that managed-care premiums are not much lower than traditional

David M. Cutler is Professor of Economics, Harvard University, and Research Associate, National Bureau of Economic Research. Louise Sheiner is an Economist at the Board of Governors of the Federal Reserve System. We are grateful to Anna Long at the Health Care Financing Administration for providing us with state medical spending data and Victor Fuchs for helpful comments. This research was supported by the National Institute on Aging and the Commonwealth Fund through grants to the NBER. This paper does not necessarily reflect the views of the members or staff of the Board of Governors of the Federal Reserve. 
indemnity premiums (Krueger and Levy 1996), so the savings from enrollment shifts to managed care alone may not be that great. Further, managed-care enrollment in many parts of the country is still very low. Finally, the growth of public health programs has slowed as wellwith both Medicare and Medicaid growing more slowly over the past few years than over the previous decade. Medicare has little managedcare enrollment, and although some have pointed to the growth of managed care as responsible for less-rapid cost growth in Medicaid, initial analysis indicates this was not the primary factor (Holahan and Liska 1997). ${ }^{1}$

And even if managed care is the answer, it is not clear whether this reduced rate of cost growth can continue. Continued excess capacity in the health system bodes well for future managed-care cost reductions. Hospital occupancy rates, for example, which were $78 \%$ in 1980, were $66 \%$ in 1995 , even with a $12 \%$ reduction in hospital beds. In the presence of excess capacity, managed-care insurers find it easier to bargain among providers and achieve overall lower rates. But there is some concern that the increasing consolidation of the medical care sector may reduce the ability of managed-care insurers to bargain among providers.

More fundamentally, however, managed care may not be addressing the right problem. Managed-care insurers may lower the rates paid for particular services and may even chip away at the margins of medical care-for example, in reduced hospital stays. But the fundamental drivers of medical costs in the next several decades will be aging and medicine's expanding technological capability. The latter factor in particular has accounted for the bulk of the growth of medical costs historically, and it is not clear that managed care has done, or can do, much about this. Managed care may save money, but how much and for how long?

In this chapter, we examine whether managed care has affected the growth of medical costs, and if so, whether that effect will continue or slow down. We take advantage of the dramatic variation in the medical insurance environment across states. Managed care is the dominant (if not the only) source of medical insurance in some states; in California, for example, close to $80 \%$ of the population is enrolled in managed care. In other states, such as Alaska or Wyoming, managed care is

1. For example, growth in spending for the elderly and the blind (who are generally not enrolled in managed care) fell more than spending for children and adults. 
virtually nonexistent. This variation in managed-care penetration provides a natural laboratory in which to examine the source of cost savings.

We conclude that managed care has slowed the growth of medical costs. States with high managed-care enrollment have significantly lower cost growth than states with lower managed-care enrollment. Managed care most affects hospital spending growth. Increased spending on physicians offsets some of the reduced hospital spending growth, but we typically find a net reduction in total spending growth. Perhaps more importantly, we find suggestive evidence that managed care may be reducing the diffusion of new medical technologies. States with high managed-care enrollment were technology "leaders" in the early 1980s but were only average in their use of technology in the early 1990s. This suggests that managed care may have a significant effect on the long-run growth of medical costs.

\section{The Growth of Aggregate Medical Spending}

We begin by analyzing recent changes in national health expenditures to examine whether there is any relation between increased competition and reduced medical spending growth. Figure 3.1 shows the growth of real, per capita national health expenditures for various time periods from 1960 through 1995. (Throughout the chapter, dollar amounts in real terms are adjusted using the GDP deflator for personal consumption expenditures.) Between 1960 and 1990, medical expenditures grew about $5 \%$ per year in real, per capita terms. The growth rate varied by decade. In the 1960s, growth was rapid, as Medicare and Medicaid were created and insurance coverage for the privately insured became more generous. In the 1970s, the medical sector consolidated and growth rates ebbed. The 1980s were marked by the first serious efforts at cost containment, including prospective payment for hospitals in the public sector and some of the private sector. But overall cost growth continued relatively unabated.

In the 1990s, however, and particularly since 1992, the growth of medical costs has slowed dramatically. In 1992, medical spending grew $4.8 \%$. In 1993, growth was $3.1 \%$; in 1994, it was $1.5 \%$; and in 1995, it was $2.1 \%$. This reduction in growth is particularly surprising given the ongoing economic expansion of the post-1992 period. (As we show below, the elasticity of medical spending with respect to income is about 1 ). Growth rates this low are thus extremely unusual historically. 


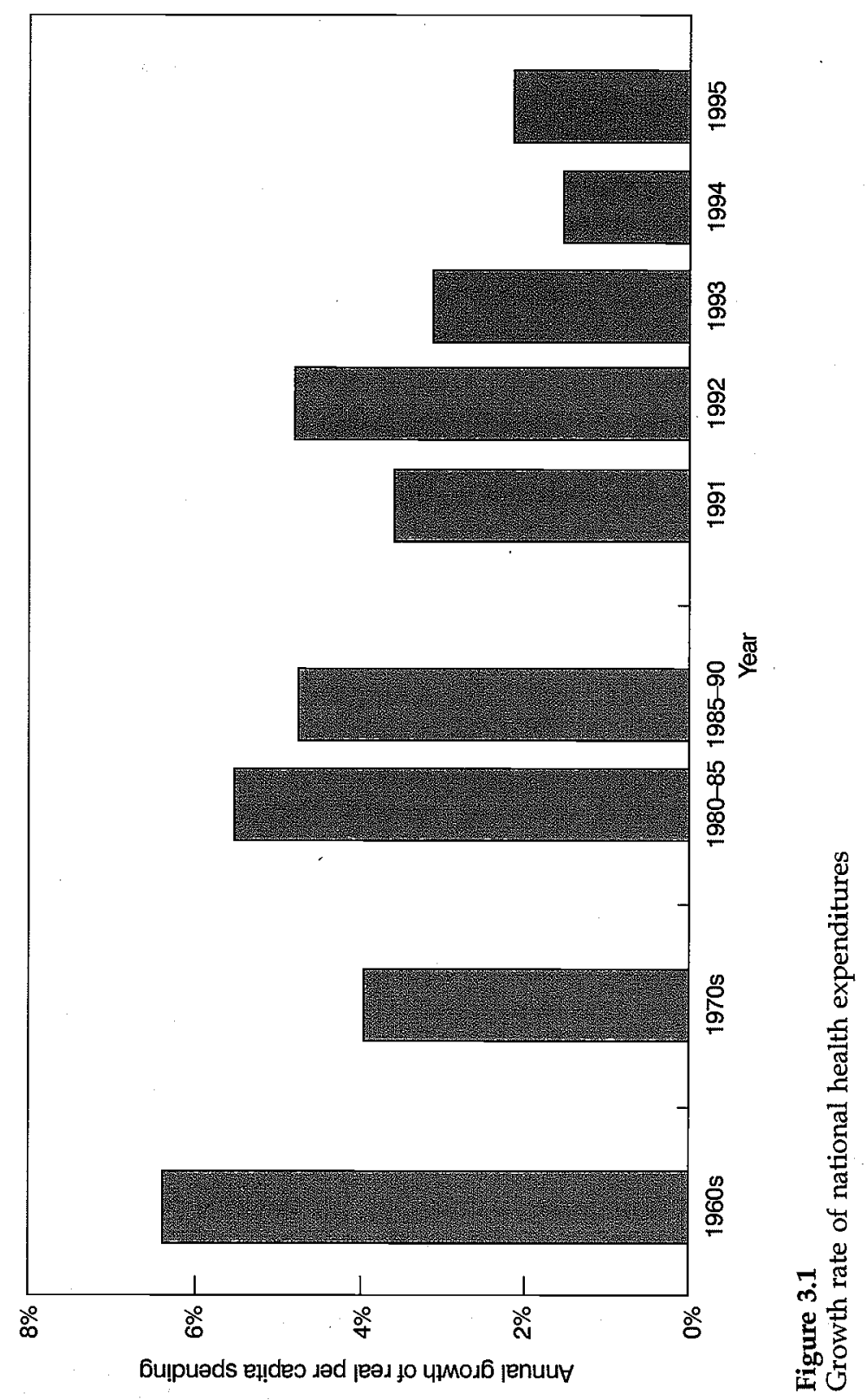




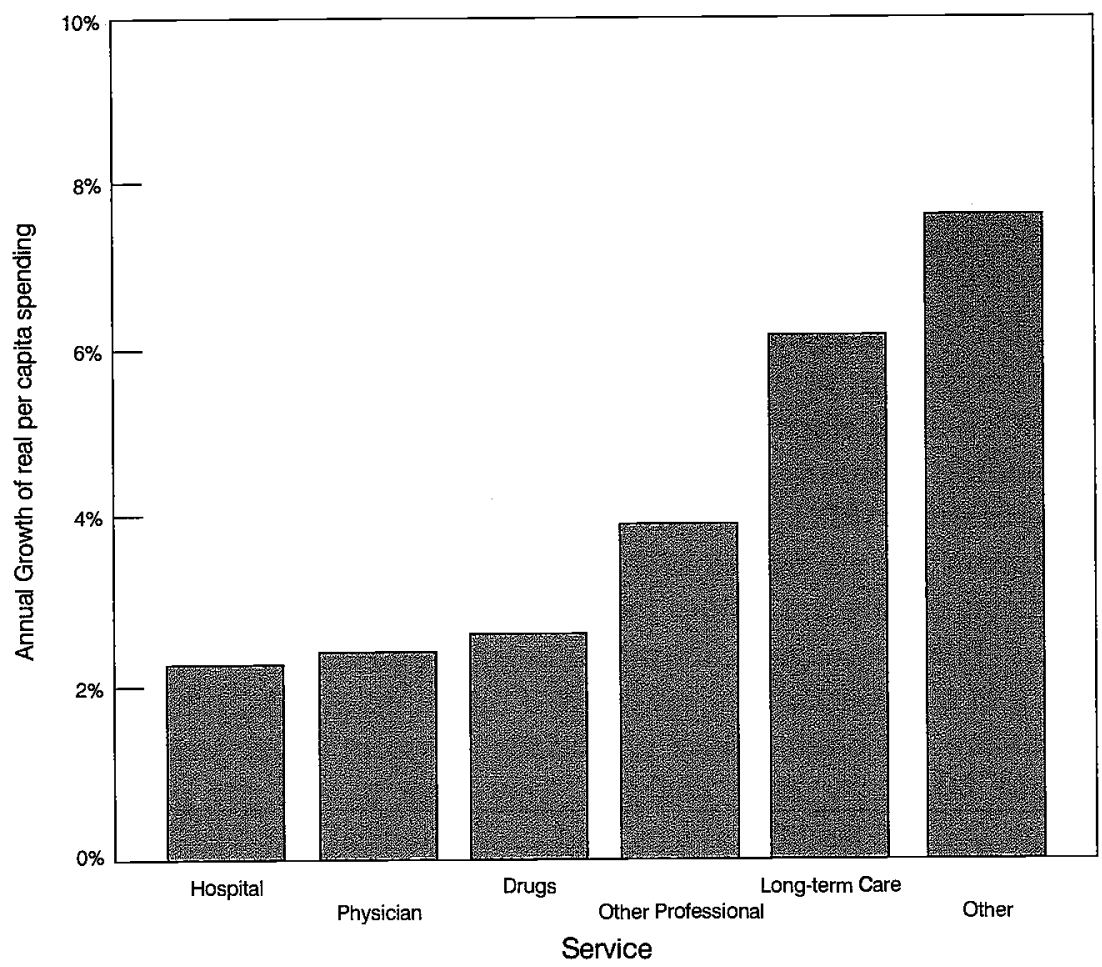

Figure 3.2

Growth of medical spending by service, 1990-1995

To offer more insight into why medical expenditure increases have been so low, figure 3.2 shows the growth in medical spending by service from 1990 to 1995 . Acute-care spending (hospitals, physicians, and prescription drugs) has grown most slowly-each category about $2.5 \%$ per year. Together, these services account for about two-thirds of medical costs. Other professional services, long-term care services, and other spending have slowed by much less.

\section{The Managed Care Explanation}

A common depiction in newspapers and professional journals is that increased enrollment in managed care has resulted in the reduction in spending growth. The insurance environment has changed enormously over the past several years. In 1980 , about $5 \%$ of the privately 
insured population was in managed care. ${ }^{2}$ By 1987, managed care accounted for about one-quarter of the privately insured population (Gabel et al. 1987); today more than three-quarters of the privately insured population is enrolled in managed care (Jensen et al. 1997).

Of course, many types of health insurance plans fall under the rubric of "managed care." A fee-for-service plan with some utilization review, for example, may call itself a managed-care plan. Still, the change in plan enrollments has been impressive. Enrollment in the most restrictive form of managed care-health maintenance organizations [HMOs]-rose from 16\% of insured workers in 1987 to $48 \%$ in 1995 (including point-of-service plans). ${ }^{3}$ Enrollment in preferred provider organizations [PPOs], the next-most-restrictive form of managed care, rose from $11 \%$ in 1987 to $25 \%$ in 1995.

Managed care can reduce medical cost growth through three mechanisms. First, managed care might negotiate price reductions. Because much of a physician's earnings are a return on past investment, managed care can often induce physicians to accept lower fees than they would otherwise have charged. The same is true for prescription drugs, some hospital services, and some medical durables. These discounts reduce medical costs. ${ }^{4}$ These will be one-time savings: As prices fall, medical spending growth will slow, but after the return to past investment has been squeezed out, medical costs will resume their increase.

Managed care might also save money through one-time quantity reductions. For example, managed-care insurers monitor very carefully the number of days that their enrollees are in the hospital. If stays can be reduced by a day, costs fall..$^{5}$ Again, however, these are likely

2. Even with the managed care available, there was little competition with indemnity insurers. Employers often subsidized indemnity policies heavily, blunting the incentives for HMOs to limit spending.

3. The distinction between HMOs and other forms of managed care has become less clear over time. In general, however, HMOs require participants to receive care from particular providers and typically pay primary-care physicians on a salary or capitated basis. Preferred provider organizations pay their providers on a discounted fee-for-service basis but may also monitor physician behavior to exclude physicians who do not keep utilization down. In both types of plans, cost sharing to the insured for using a provider in the insurer's network is lower than for using providers outside the network. 4. These price reductions may have long-term effects on the supply of new physicians or medical equipment, but we ignore that issue in this chapter.

5. Again, this change may have long-term effects on the number of hospitals, the structure of the hospital industry, and the like, but for our purposes, we ignore these effects. 
to be one-time savings. Lengths of stay can fall only so much; when they cease falling, medical costs will continue to increase.

Finally, managed care might save money by reducing the rate of technology expansion-the intensity with which a typical patient is treated or the rate at which new technologies are adopted. We separate this factor from the first two because of its importance in the long-run growth of medical spending. Much research shows that the dominant source of increasing medical costs over time is the development of new medical technologies and the application of existing technologies to new patients (Aaron 1991; Newhouse 1992; Cutler and McClellan 1996). If managed care reduces the expansion of technologies, it could have a long-term effect on the growth of medical costs.

Quantity changes resulting from managed care-either one-time savings or reductions in the rate of technology diffusion-may either improve or reduce welfare. To the extent that managed care reduces the resources needed to provide a given level of medical services, that would be an efficiency savings to society. If managed care changes the amount of services provided, however, welfare may either rise or fall, depending on whether the services no longer provided were worth more or less than their cost. In this chapter, we look only at the effects of managed care on overall resource utilization, without drawing strong conclusions about the value of those changes.

\section{Testing the Managed-Care Effect}

One piece of evidence suggesting that managed care has reduced national medical expenditures in the past few years is that managedcare premiums are lower than premiums in traditional indemnity policies. A recent Foster Higgins report, for example, found that in 1995 , costs for HMOs were either flat or declining, whereas costs for traditional insurance continued to rise. Hay-Huggins reports that HMO premiums are significantly lower than premiums for fee-forservice insurance, although other surveys show smaller differences (Krueger and Levy 1997). Wholey, Feldman, and Christianson (1995) examine the impact of HMO concentration on changes in HMO premiums and find that more HMO competition leads to lower HMO premiums.

But this evidence is not conclusive. The fact that managed care pays less than indemnity insurers does not mean that total medical 
spending is lower. Providers might simply reduce their costs to managed-care insurers and raise them to indemnity insurers to offset the managed-care discount. This type of substitution is broadly believed to occur when Medicare and Medicaid cut spending. Or managed care might reduce spending for covered services, but spending for uncovered services might rise. On the other hand, if competition induces changes in practice styles so that HMOs have a moderating effect on both HMO and traditional indemnity premiums, ${ }^{6}$ then comparing HMO to fee-for-service premiums may understate managed care's impact on health expenditures.

We estimate the systemwide savings from managed care by looking at overall medical spending growth in states where managed care is more prevalent compared to states where managed care is less prevalent. If managed care reduces medical spending growth, this should be apparent through such a comparison.

Figure 3.3 shows a first pass at this comparison. We show per capita spending relative to the national average in California and Minnesota-two states in the vanguard of the managed-care revolution-between 1980 and 1993. In both states, spending growth was much lower than the national average. In California, for example, per capita medical spending was 17\% above the national average in 1980; by 1993 spending was equal to the national average. In Minnesota, medical spending fell from $9 \%$ above the national average to $4 \%$ above the national average over the same period.

Melnick and Zwanziger (1995) and Zwanziger and Melnick (1996) compare in detail the experience of California with that of the rest of the nation. They show that in the 1980s, spending on all acute-care services rose less rapidly in California than in the nation as a whole, as did numbers of full-time-equivalent hospital employees per patient and the average length of a hospital stay.

To examine this issue more systematically, we use data on state medical spending between 1980 and 1993 from the Health Care Financing Administration. (See Levit et al. (1995) for a description of the data.) Unfortunately, no more recent data on cross-state spending are available; thus, we cannot examine managed care's effects in the period in which the national changes in spending were the greatest. We

6. For example, Wickizer and Feldstein (1995) found that premiums for fee-for-service insurance were lower in areas with higher HMO enrollment. Baker (1997) found that Medicare fee-for-service payments were lower in areas with more managed care. 


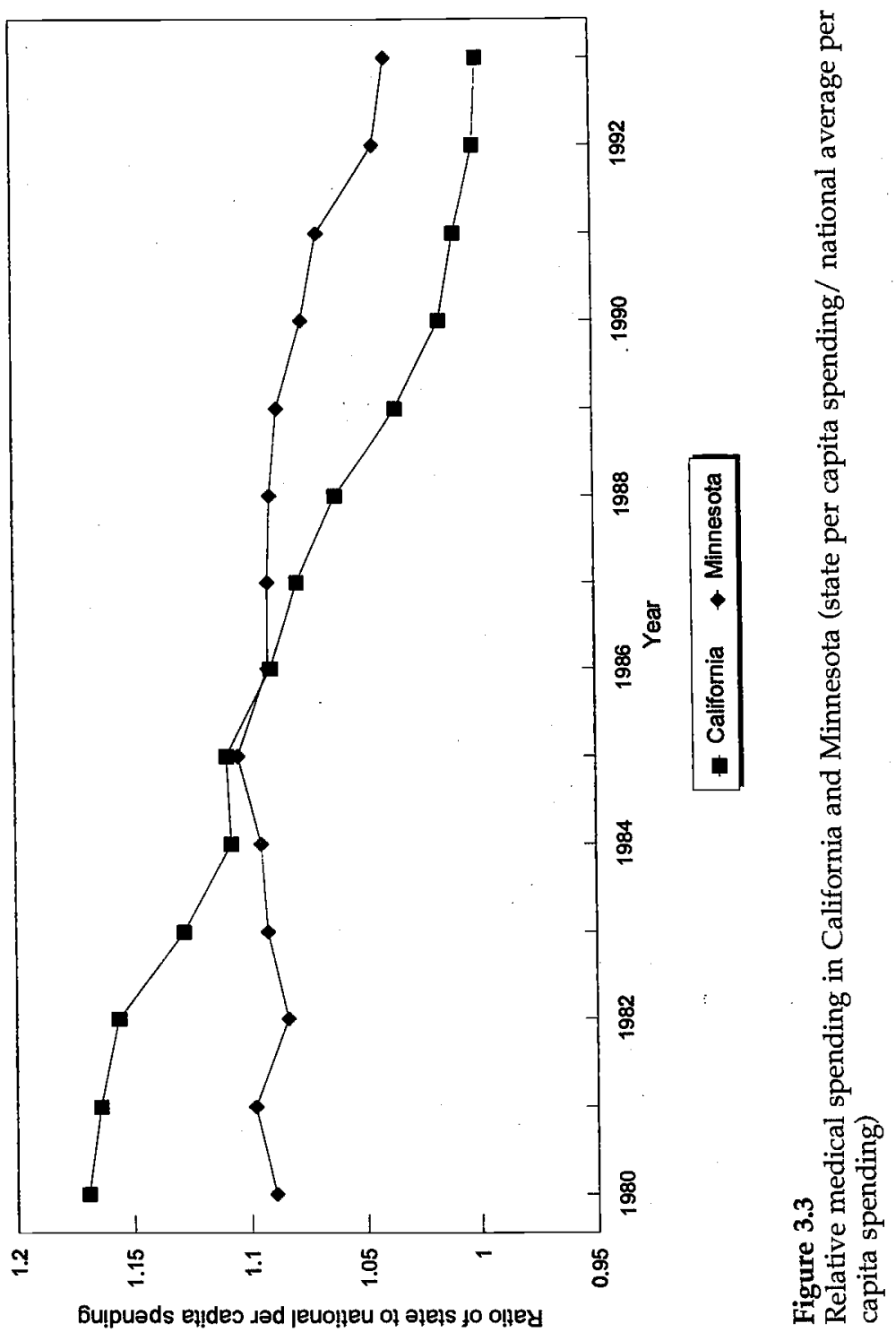


measure HMO enrollment as the average value, from 1980 to 1993, of HMO enrollment per capita (HMO enrollment data are from Interstudy).

Table 3.1 shows summary statistics for the data. The average state had spending growth of $4.6 \%$ in real per capita terms between 1980 and 1993, with hospital spending growing less rapidly than physician spending. HMO enrollment averaged $11.2 \%$, but ranged from $0 \%$ to 28\%. (HMO enrollment includes both "pure" enrollment (closed-panel HMOs) and "open" enrollment (plans with a point-of-service option)). Although there are many other forms of managed care beyond HMOs, consistent data on non-HMO managed care are not available over time. We also suspect that HMO enrollment is correlated with managed-care enrollment more generally. The states with the highest HMO enrollments are California, Minnesota, Hawaii, Oregon, and Massachusetts. Those with the lowest HMO enrollments are small or rural states such as Alaska, Mississippi, and Wyoming, with no HMO enrollment or a very small amount.

Figure 3.4 shows the national analog of figure 3.3. We graph the change in real per capita medical expenditures for each state against average HMO enrollment. The two have a clear negative relation, consistent with the managed-care explanation. States with high HMO enrollment had less-rapid spending growth. The correlation between cost growth and HMO enrollment, shown in the bottom of table 3.1, is -6. And a simple regression equation gives a large magnitude: Each ten-percentage-point increase in HMO enrollment reduces cost growth by .6 percentage points annually. ${ }^{7}$

Before being convinced by figure 3.4, however, we must question why managed-care enrollment is so high in some states and so low in others. Both managed-care enrollment and subsequent spending growth may respond to a third factor-the initial level of medical spending in the state. In states where costs are high, managed care will enroll new members more easily than in states where they are low. But this relationship is problematic if states with high medical costs naturally would have had less-rapid growth of medical costs in the future, perhaps because other states would catch up to their more advanced

7. All of our correlations and regressions weight the observations by population. Without such weighting, HMOs would not have as large or significant an effect on expenditures (both because states like Alaska, Nevada, and Hawaii are outliers but have very small populations and because weighting the regressions places more weight on California). 


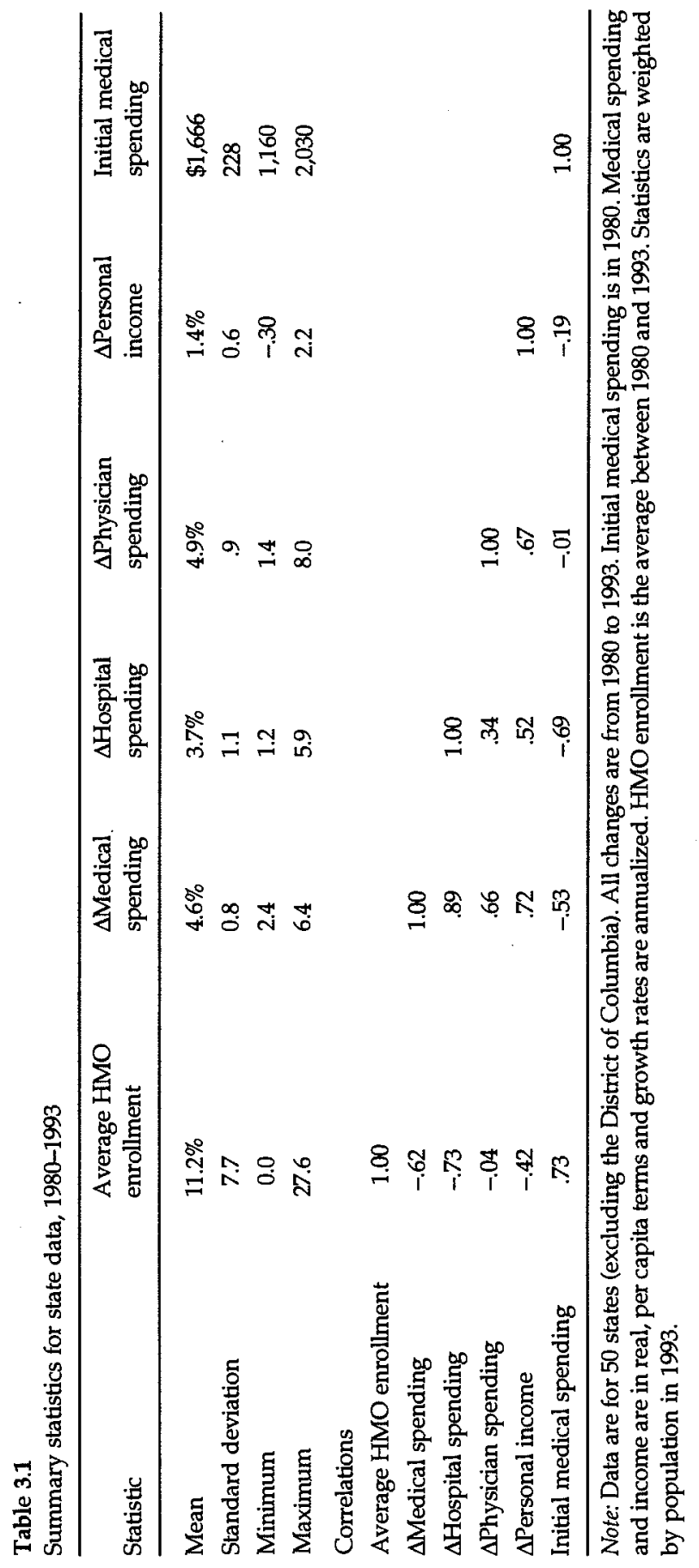




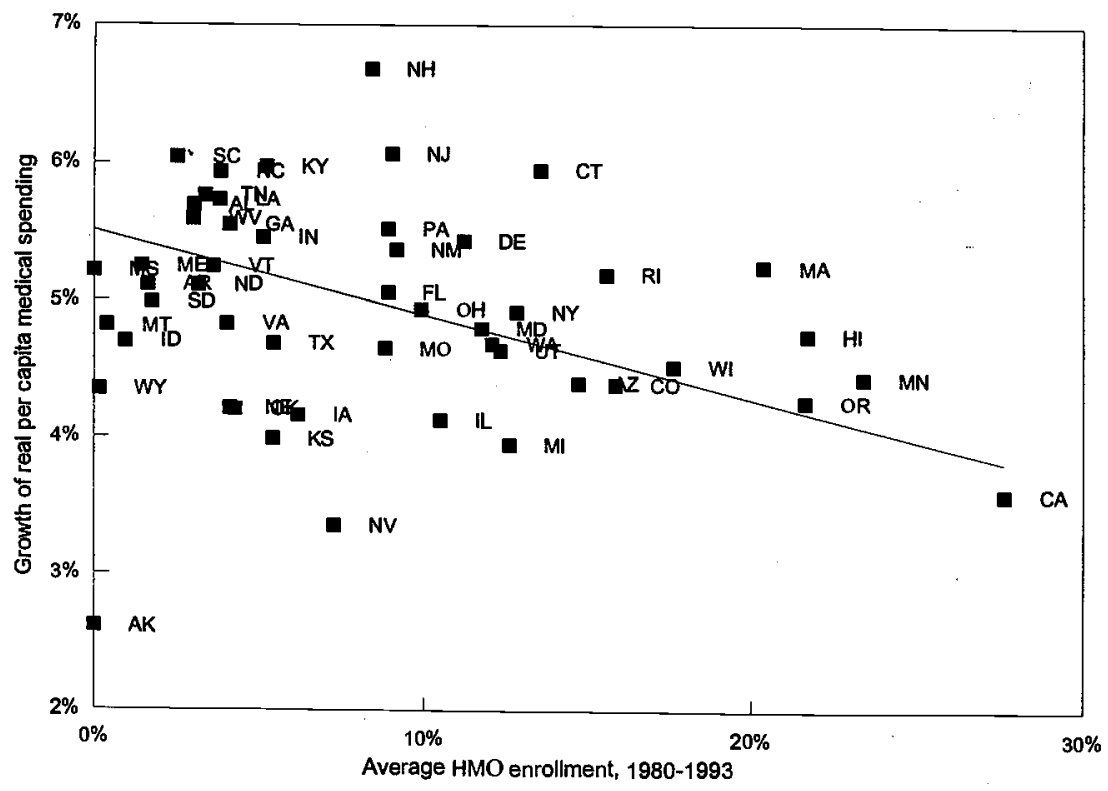

Figure 3.4

HMO enrollment and the growth of medical spending, 1980-1993

medical practices. Indeed, as figure 3.3 showed, medical expenditures in California slowed just enough to bring California spending back to the national average from the extremely high levels observed in the early 1980s.

Figures 3.5 and 3.6 suggest this is a more general phenomenon. Figure 3.5 shows the relation between per capita medical spending in 1980 and average HMO enrollment between 1980 and 1993. Initial spending and managed-care enrollment are positively related; the correlation between them, shown in table 3.1, is .73. Figure 3.6 shows that initial medical spending is also associated with reductions in the growth of future medical spending. Again, the correlation is large (-.53).

The important question, then, is whether managed-care enrollment really reduces the growth rate of medical spending or whether it instead proxies for states with high initial spending, which naturally have less rapid growth rates over time. In the next section, we address this issue. 


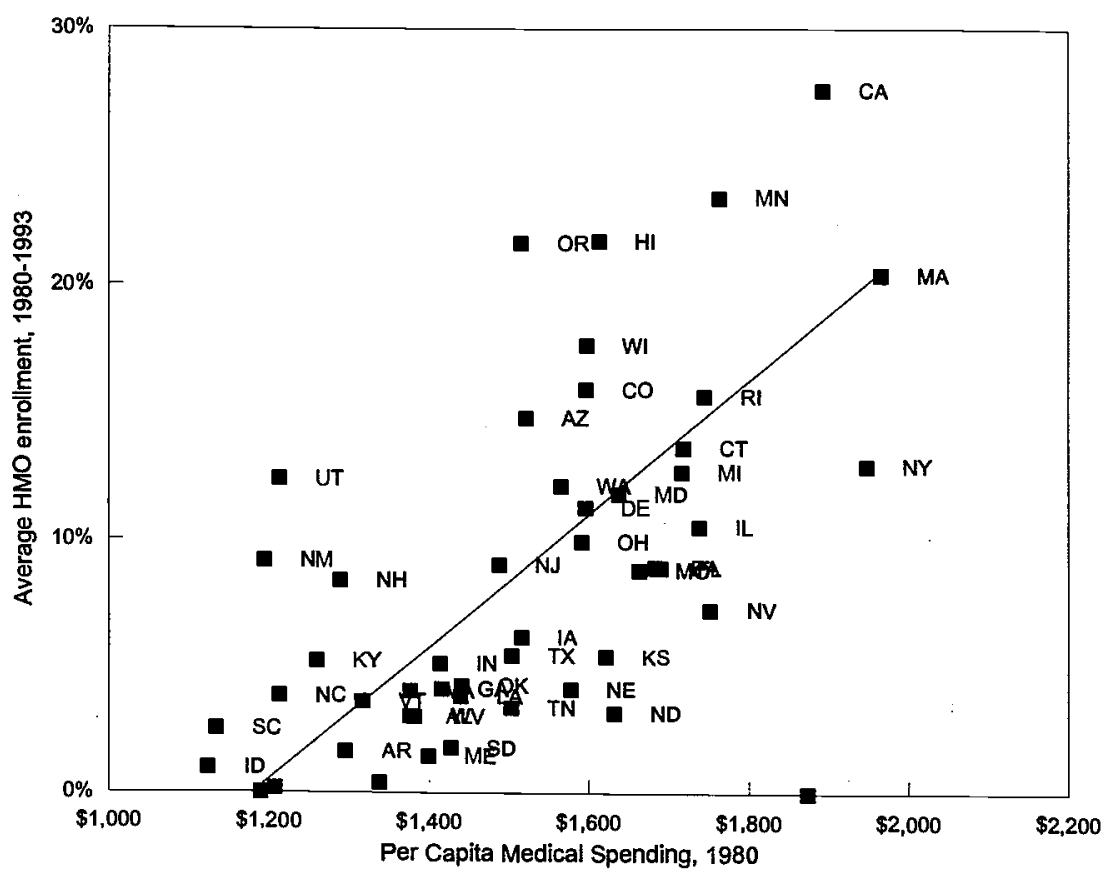

Figure 3.5

Initial medical spending and average subsequent HMO enrollment

\section{Explaining State Cost Growth}

To estimate the effect of managed care on the growth of state medical costs, we consider the regression analogue to figure 3.4:

$\Delta$ Spending $_{s}=\beta_{1}$ HMO Enrollment $s+X_{s} \beta+\varepsilon_{s}$

where $s$ denotes states and the dependent variable is the annualized growth rate of real, per capita medical spending in the state from 1980 to $1993 . \beta_{1}$ is the effect of HMO enrollment on annual cost growth.

We examine managed care's impact on a number of components of spending-total medical spending, spending on hospitals, spending on physicians, and spending on prescription drugs. We also examine its impact separately on Medicare and non-Medicare expenditures. Ideally, we would like to measure managed care's impact on the per capita spending of privately insured individuals, but those data are not available. Non-Medicare expenditures are a decent proxy, but in addition to the health expenditures of privately insured individuals, non-Medicare expenditures include out-of-pocket expenditures of the 


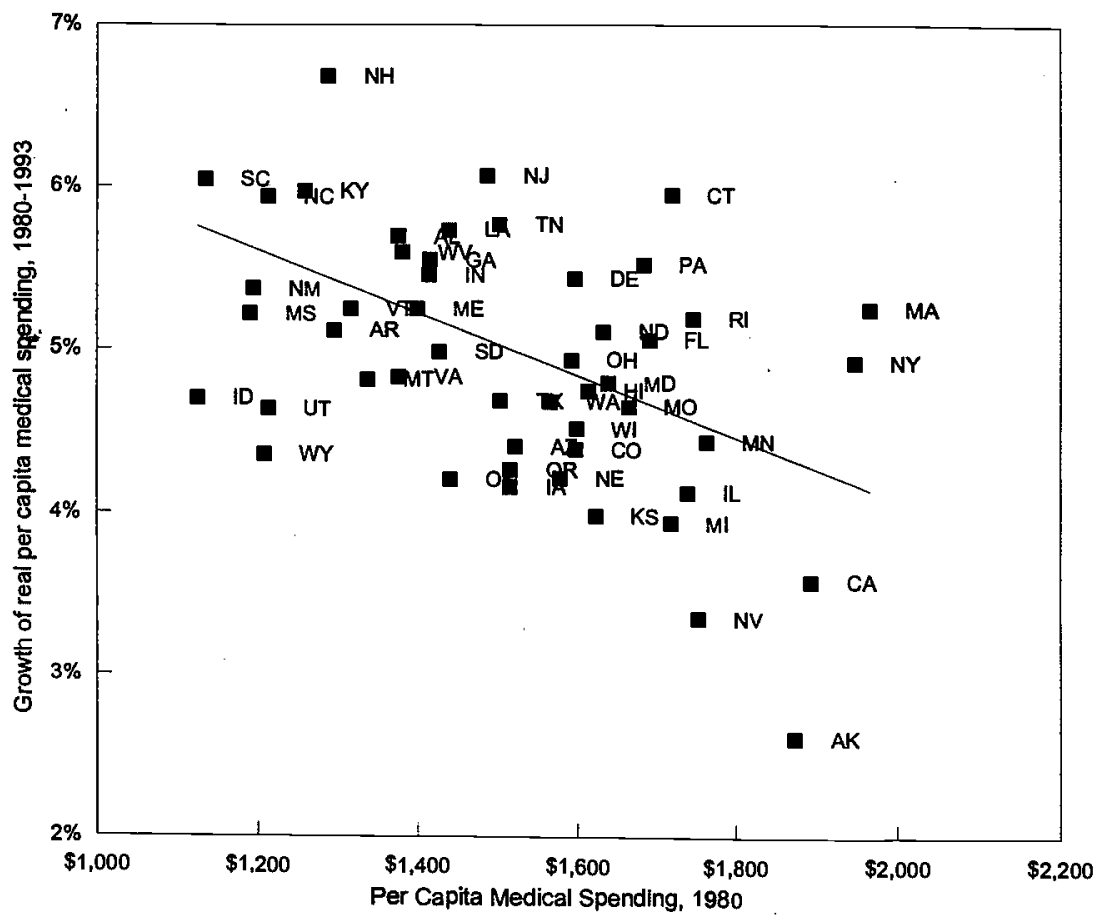

Figure 3.6

Reversion of medical spending

elderly and the uninsured and expenditures paid by Medicaid or other government programs.

It is not clear whether the level or the change in HMO enrollment should be related to the growth of spending. In theory, the level of managed care could affect both the level of spending, through onetime efficiency gains or reimbursement cuts (so the change in HMO enrollment would be related to the change in spending), or the growth rate of spending, by changing the speed at which technology is adopted (so the level of HMO enrollment would explain changes in spending). In practice, however, the one-time effects of high HMO enrollment likely occur over a number of years, so that the level of managed-care enrollment in a state is likely to affect the growth rate of spending regardless of whether HMOs affect technology adoption. Further, the change in HMO enrollment might affect spending only with a lag. For these reasons, we have decided to use the average level of $\mathrm{HMO}$ enrollment over the period in our regressions. As figure 3.7 


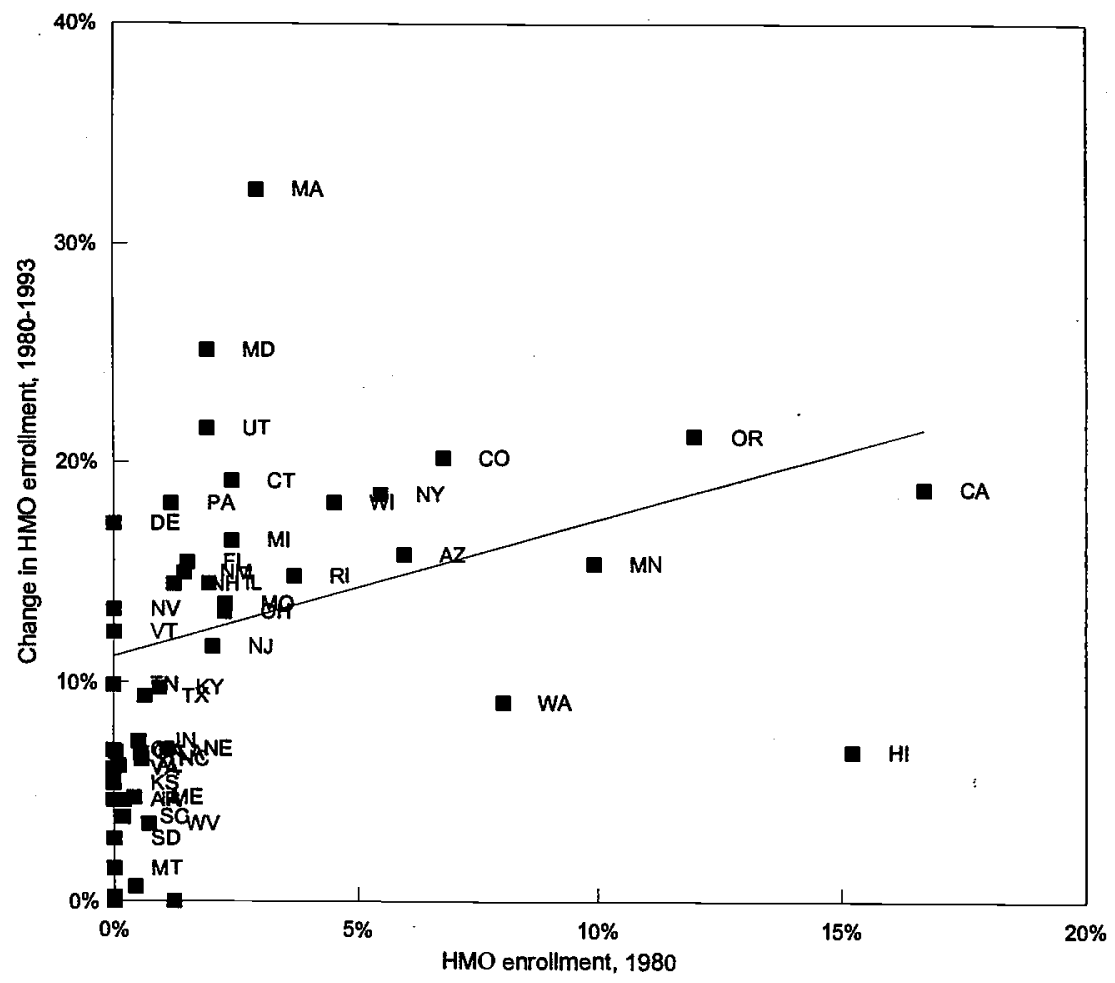

Figure 3.7

Level and growth of HMO enrollment

shows, however, the change in HMO enrollment is closely correlated with the level of HMO enrollment in 1980; in general, our results hold equally well when we use the change in HMO enrollment instead of the level. ${ }^{8}$

The other right-hand-side variables included in the regression are the change in per capita income, because people with higher incomes spend more on health care (Newhouse and the Insurance Experiment Group 1993), and demographic controls (the change in fraction of the population 18 or younger and the change in fraction of the population 65 or older).

8. The level of HMO enrollment has a sufficiently high correlation with its growth rate that the standard errors increase substantially when we include both in the regression simultaneously. 
Table 3.2 presents regression results for total health spending over 1980-93. The first four columns show figures without controlling for initial spending; the second four columns include such controls. In general, the coefficients on the control variables are as we would expect. Income growth is positively related to spending growth; the elasticity is about 1. An increasing share of older people is associated with increased medical spending, whereas an increasing share of younger people has no effect on spending growth.

The first row shows the effect of HMO enrollment on cost growth. When initial spending levels are not controlled, HMOs have a significant negative effect on total health spending. Every ten-percentagepoint increase in HMO enrollment reduces the growth of health expenditures by 3 percentage points per year. ${ }^{9}$ The effect works only through hospital spending-increased HMO enrollment is actually associated with increased spending on physicians and prescription drugs.

Consistent with our figures above, controlling for initial spending reduces HMOs' impact on cost growth. Initial spending has a strong negative effect on subsequent spending growth; each $10 \%$ increase in spending in 1980 is associated with cost growth between 1980 and 1993 that is .2 percentage points below average. Whatever the source of this convergence, it is not a new phenomenon. As reported in table 3.3, growth of medical expenditures across states exhibited the same pattern from 1966 to 1980. Controlling for this phenomenon is important and affects our estimates of managed care's impact on health costs. Returning to table 3.2, when we control for initial spending, the coefficient of HMO enrollment on total spending is still negative (-.014) but not statistically significant. Even in this case, however, HMOs are still associated with a reduction in hospital spending; the coefficient is large (-.052) and statistically significant. But HMOs also have a positive, large, statistically significant impact on physician spending.

Clearly, one of managed care's major effects is to shift the site of care from the hospital to the physician's office or clinic (see Reinhardt 1996 for a discussion of this trend). As shown in figure 3.8, states with high $\mathrm{HMO}$ enrollments spend much less of their medical dollars in the

9. An alternative way to see this effect is to regress the logarithm of medical spending in each year on HMO enrollment that year and the control variables for that year. If we do this, we obtain a coefficient on HMO enrollment of .688 (.214) in 1980 and $.198(.125)$ in 1993. The reduction in the coefficient on HMO enrollment is consistent with the regressions in table 3.2. 


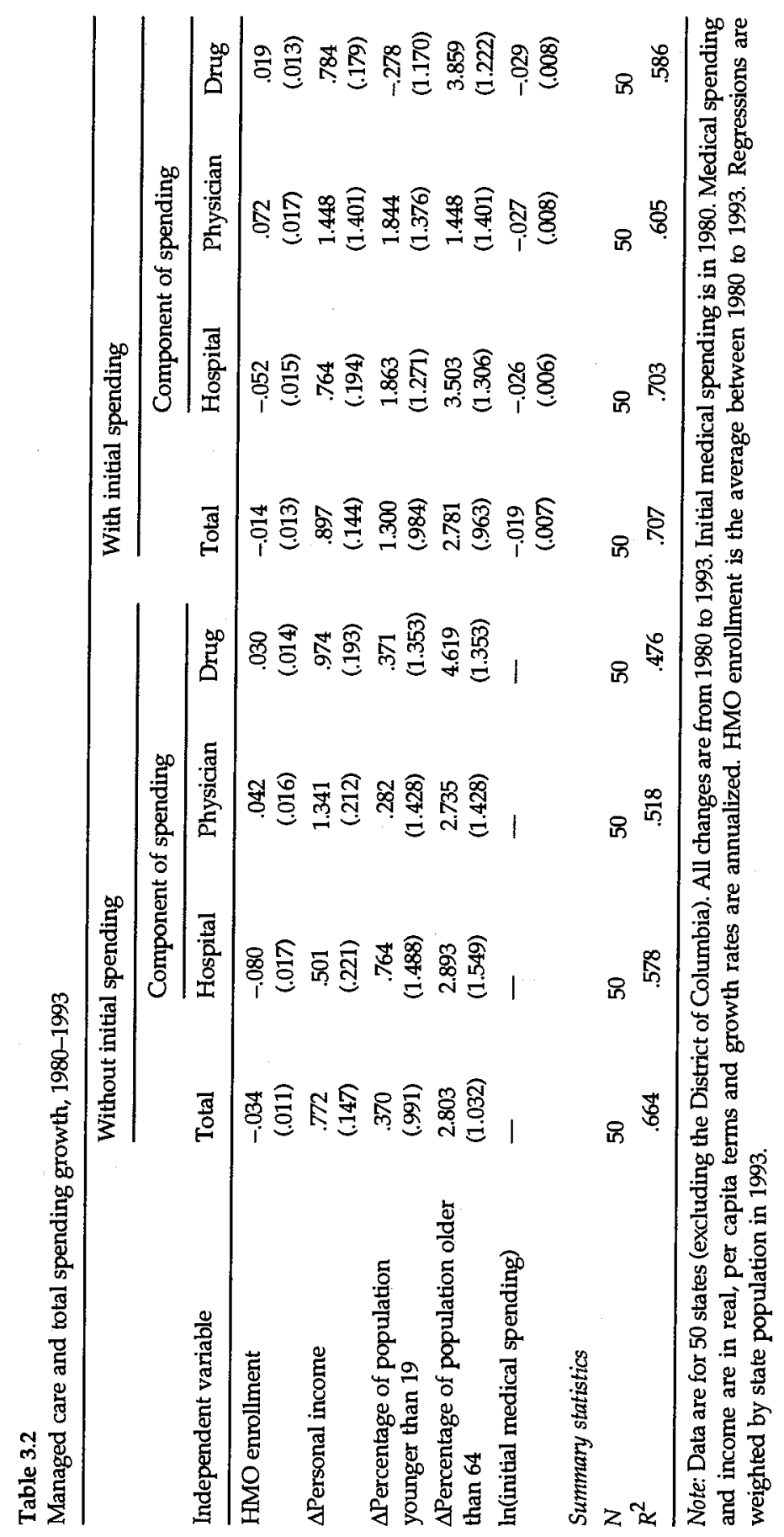


Table 3.3

Reversion of spending, 1966-1980

\begin{tabular}{|c|c|c|c|c|}
\hline \multirow[b]{2}{*}{ Independent variable } & \multicolumn{4}{|c|}{ Component of spending } \\
\hline & Total & Hospital & Physician & Drug \\
\hline HMO enrollment & - & - & - & - \\
\hline$\Delta$ Personal income & $\begin{array}{c}.213 \\
(.163)\end{array}$ & $\begin{array}{c}-.161 \\
(.208)\end{array}$ & $\begin{array}{l}1.173 \\
(.279)\end{array}$ & $\begin{array}{c}.575 \\
(.173)\end{array}$ \\
\hline$\Delta$ Percentage of population younger than 19 & $\begin{array}{c}-.036 \\
(.074)\end{array}$ & $\begin{array}{c}.122 \\
(.097)\end{array}$ & $\begin{array}{c}-.482 \\
(.129)\end{array}$ & $\begin{array}{c}.035 \\
(.092)\end{array}$ \\
\hline$\Delta$ Percentage of population older than 64 & $\begin{array}{c}.309 \\
(.087)\end{array}$ & $\begin{array}{l}.400 \\
(.113)\end{array}$ & $\begin{array}{l}.164 \\
(.148)\end{array}$ & $\begin{array}{c}.143 \\
(.106)\end{array}$ \\
\hline In(initial medical spending) & $\begin{array}{c}-.018 \\
(.005)\end{array}$ & $\begin{array}{c}-.021 \\
(.005)\end{array}$ & $\begin{array}{r}-.006 \\
(.007)\end{array}$ & $\begin{array}{r}-.042 \\
(.007)\end{array}$ \\
\hline \multicolumn{5}{|l|}{ Summary statistics } \\
\hline$N$ & 50 & 50 & 50 & 50 \\
\hline$R^{2}$ & .589 & .466 & .634 & .623 \\
\hline
\end{tabular}

Note: Data are for 50 states (excluding the District of Columbia). All changes are from 1966 to 1980 . Initial medical spending is in 1966. Medical spending and income are in real, per capita terms and growth rates are annualized. Regressions are weighted by state population in 1980 .

hospital. HMO coverage does not affect the share of spending on drugs; most of the offset is on physicians. HMOs' large impact on physician spending is somewhat surprising and is worthy of further investigation. $^{10}$

Table 3.4 shows regression analogous to those in table 3.2 for nonMedicare expenditures. The results are very similar-when we do not control for initial spending, HMOs reduce total and hospital spending but increase physician and prescription drug spending. When initial spending is included, HMOs have no significant effect on total health spending but shift spending from hospitals to physicians.

Table 3.5 examines managed care's effect on Medicare expenditures per elderly person. (Because Medicare does not pay for prescription drug coverage, only the physician and hospital results are presented.) Controlling for initial spending, the results indicate that states with high HMO enrollment (mostly of the non-Medicare population) have

10. Simon and Emmons (1997) find that physicians who are paid through capitation often do not purchase reinsurance. It is possible, then, that payments to physicians increase under managed care because physicians take on increased risk. Alternatively, some physician spending could actually be hospital spending, but under systems of capitated payments, the two may be hard to distinguish. 


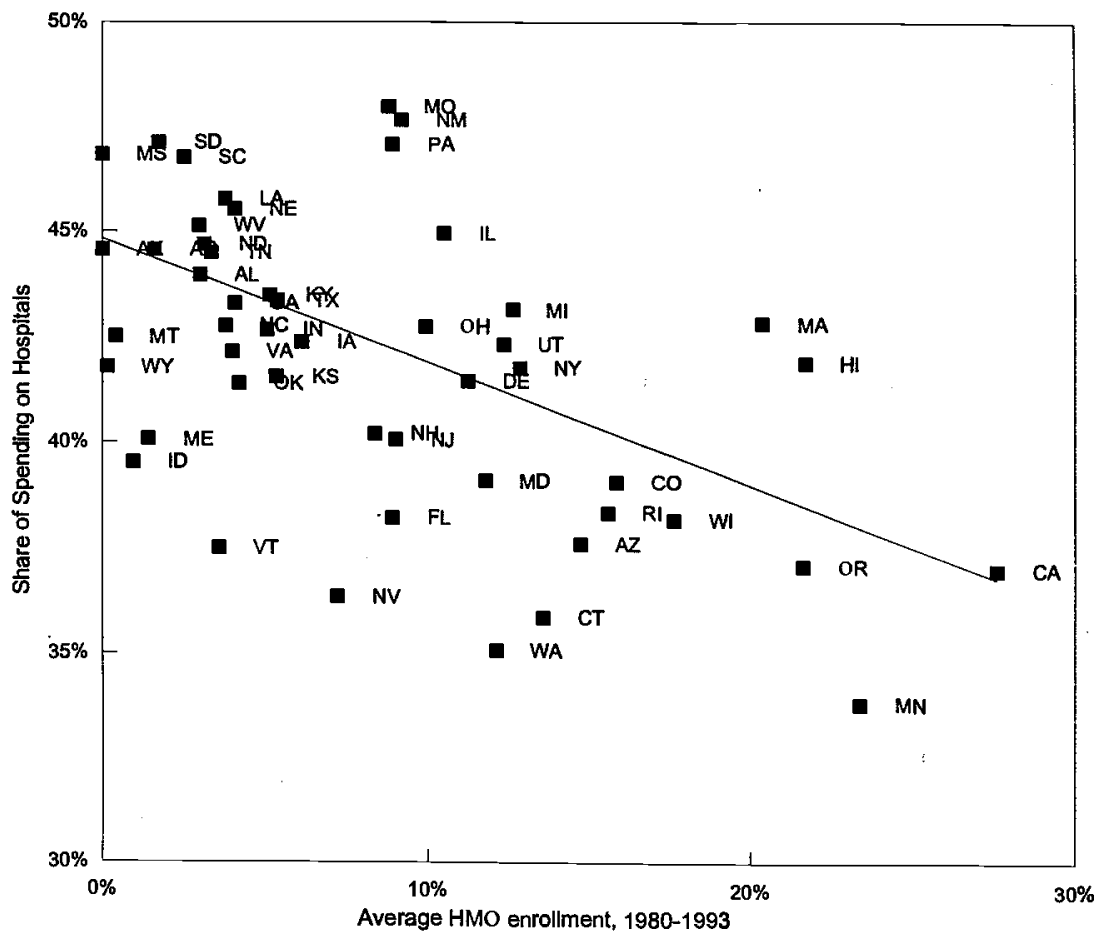

Figure 3.8

Managed care and the share of spending on hospitals

lower hospital spending growth, although the coefficient is not significant at a $10 \%$ level. HMOs have no measured effect on physicians. Because enrollment in managed care was a very small share of total Medicare enrollment in this time period, the effect of managed care on Medicare costs is not a direct effect of managed care enrollment for that group. Instead, two effects might be at work. First, to the extent that managed care affects hospital or physician practices, states with a high rate of HMO enrollment might also have lower Medicare expenditures. Second, HMOs may reduce the amount of "cost-shifting" from Medicare to private insurance, which would show up as lower overall spending and probably fewer services to the Medicare population. Further work could usefully distinguish between these effects.

Our analysis to this point raises two issues. First, the health care market has changed significantly in recent years (although some may argue that most of the changes have occurred in the years since 1993, for which expenditure data across states are not yet available), and 


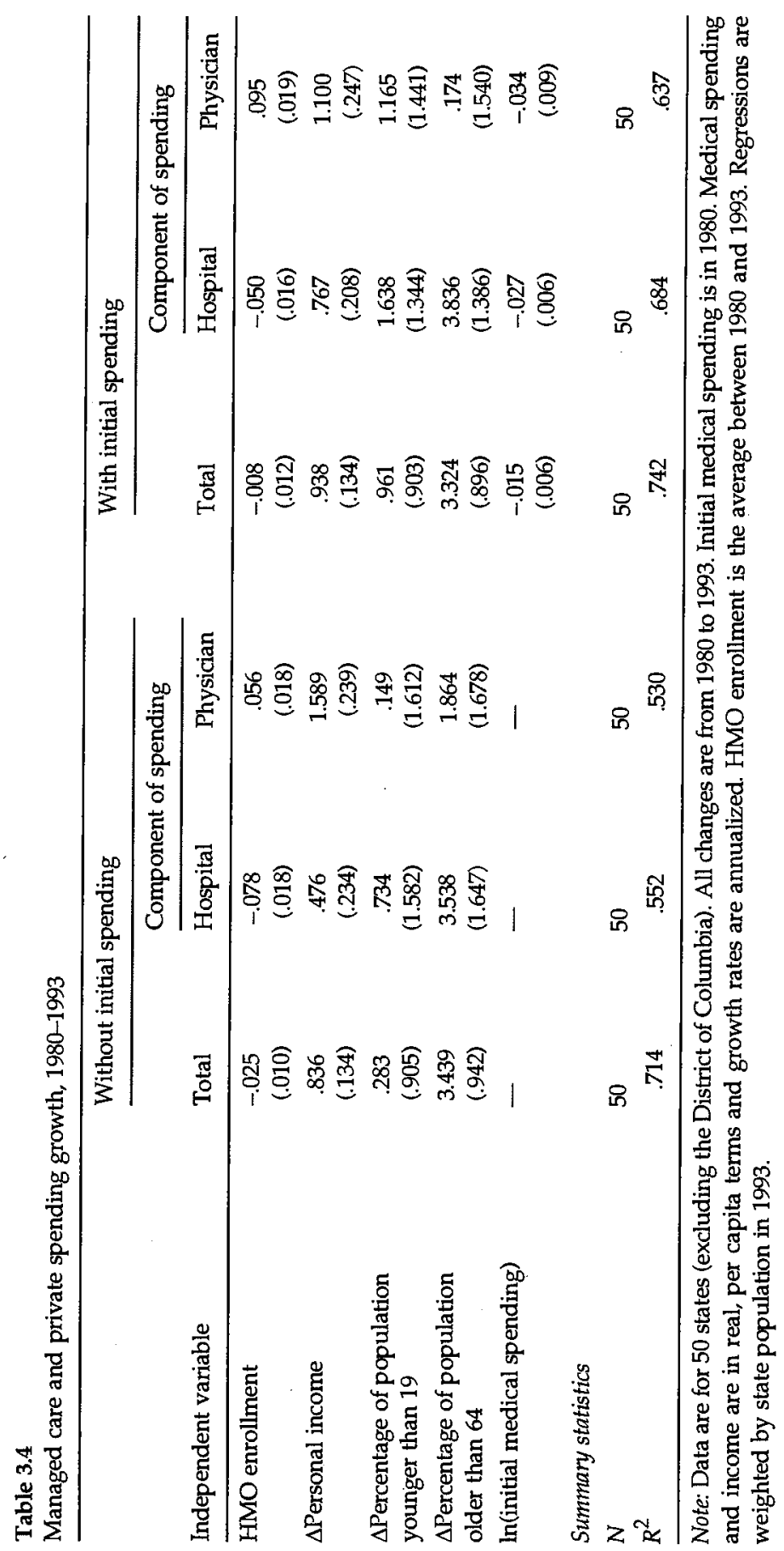




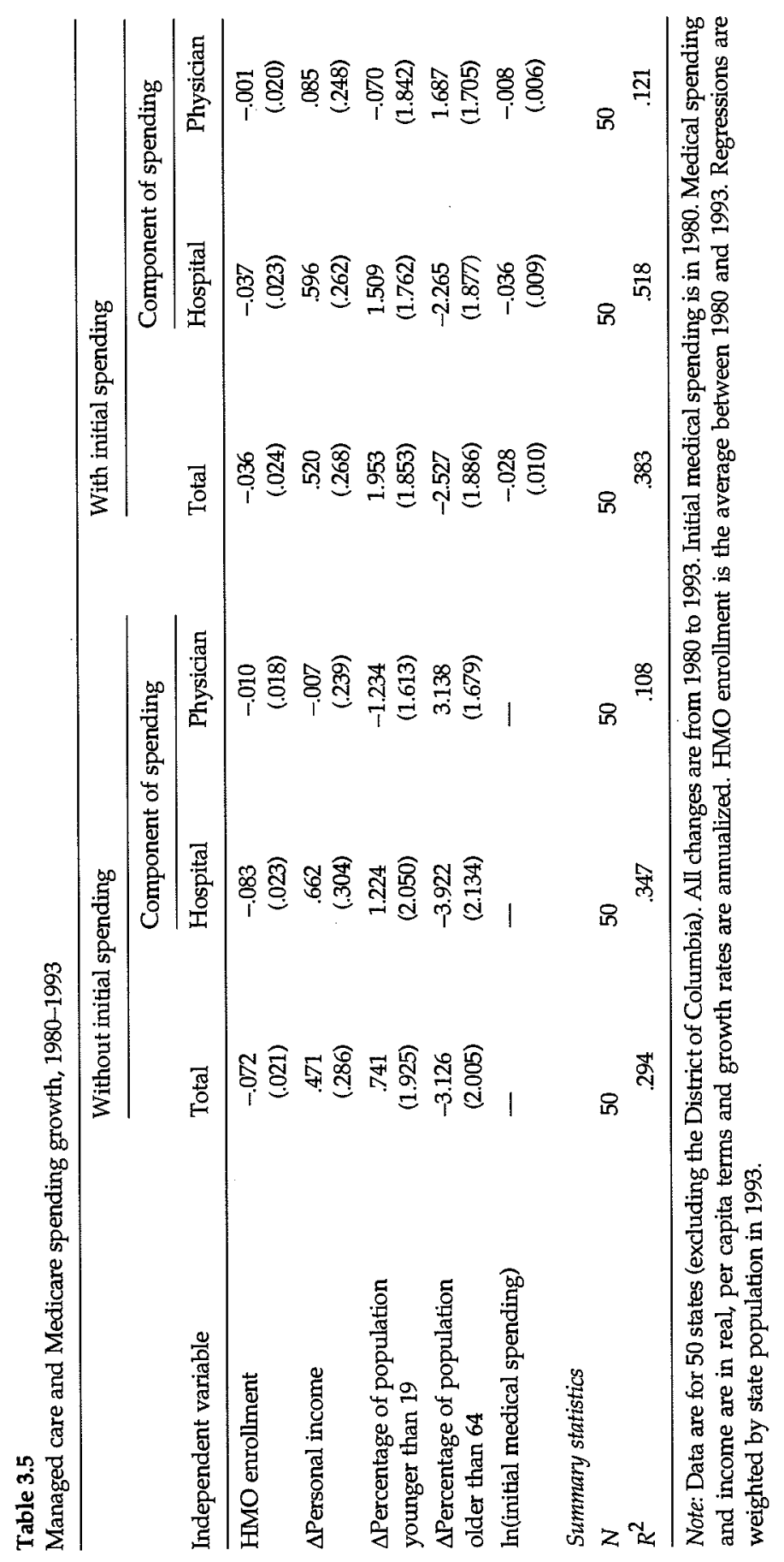


HMOs may have had increasing effects over time. ${ }^{11}$ Second, these regressions ignore another major innovation in hospital financing that occurred in the 1980s-the introduction of prospective payment in Medicare. To the extent that prospective payment equalized payments across states (moving from a payment method that relied on reasonable costs to one of fixed payments per diagnosis), this would affect hospital spending as well. Because high-HMO states were also highcost states, this may be negatively correlated with $\mathrm{HMO}$ enrollment.

To control for both of these issues, we reestimate the regressions for 1988-93 only. By 1988, prospective payment was fully phased in and managed care was well underway. Thus, this time period might be more indicative of a true managed-care effect than 1983-88. Tables 3.6-3.8 present the results. The results for total spending growth, shown in table 3.6, indicate that managed care is more effective at controlling costs in the later period than in the earlier period; there is a greater negative effect on hospital spending growth and a smaller positive effect on physician spending growth. ${ }^{12}$ The overall effect is a decline of .5 percentage points per year in total health expenditures for every ten-percentage-point increase in the HMO enrollment rate, a large effect and significantly different from zero. Table 3.7 shows similar results for private spending growth, although the positive effect of managed care on physician spending is larger and more significant. Table 3.8 shows that the results for Medicare growth again suggest a managed-care effect, but the coefficients are smaller and less significant over 1988-93 than over the entire 1980-93 period. This might indicate some confounding effects from the introduction of the Medicare Prospective Payment System (PPS) in the first part of the sample.

Overall, the cross-state evidence points to managed care as an important factor in the recent decline in health costs. Over the entire period from 1980 to 1993, we find that increases in physician spending nearly fully offset reductions in hospital spending. When we look at the most recent period, however, we find reductions in hospital spending only partly offset by increased physician spending. Our results suggest that a $10 \%$ increase in HMO enrollment reduces the growth of hospital spending by about $0.5 \%$ and that of overall medical costs

11. Gabel (1997) surveys the changes in HMOs that occurred in the 1990s.

12. Simon and Born (1996) find that managed care had no significant impact on physician earnings until 1993-94. 


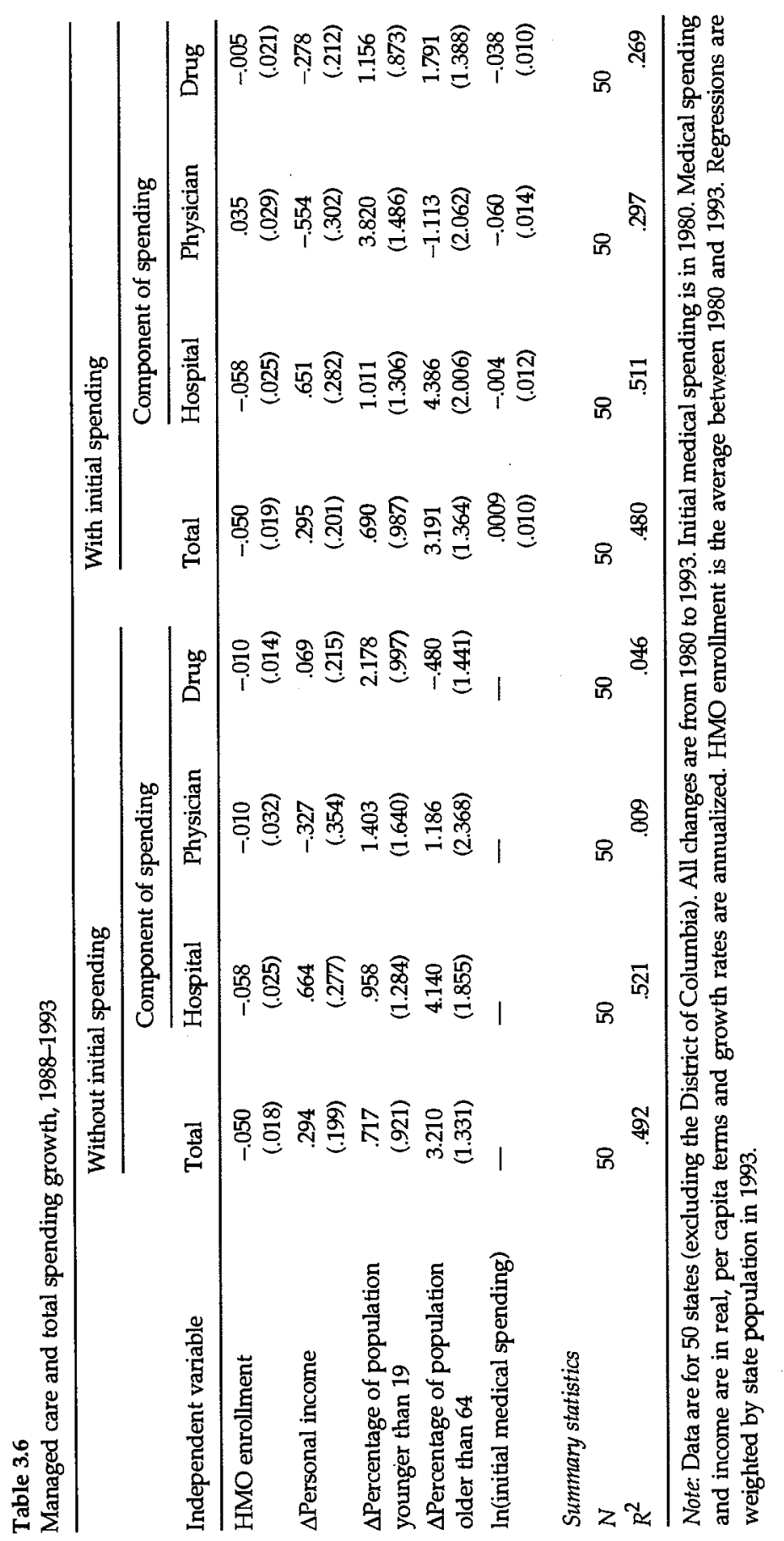




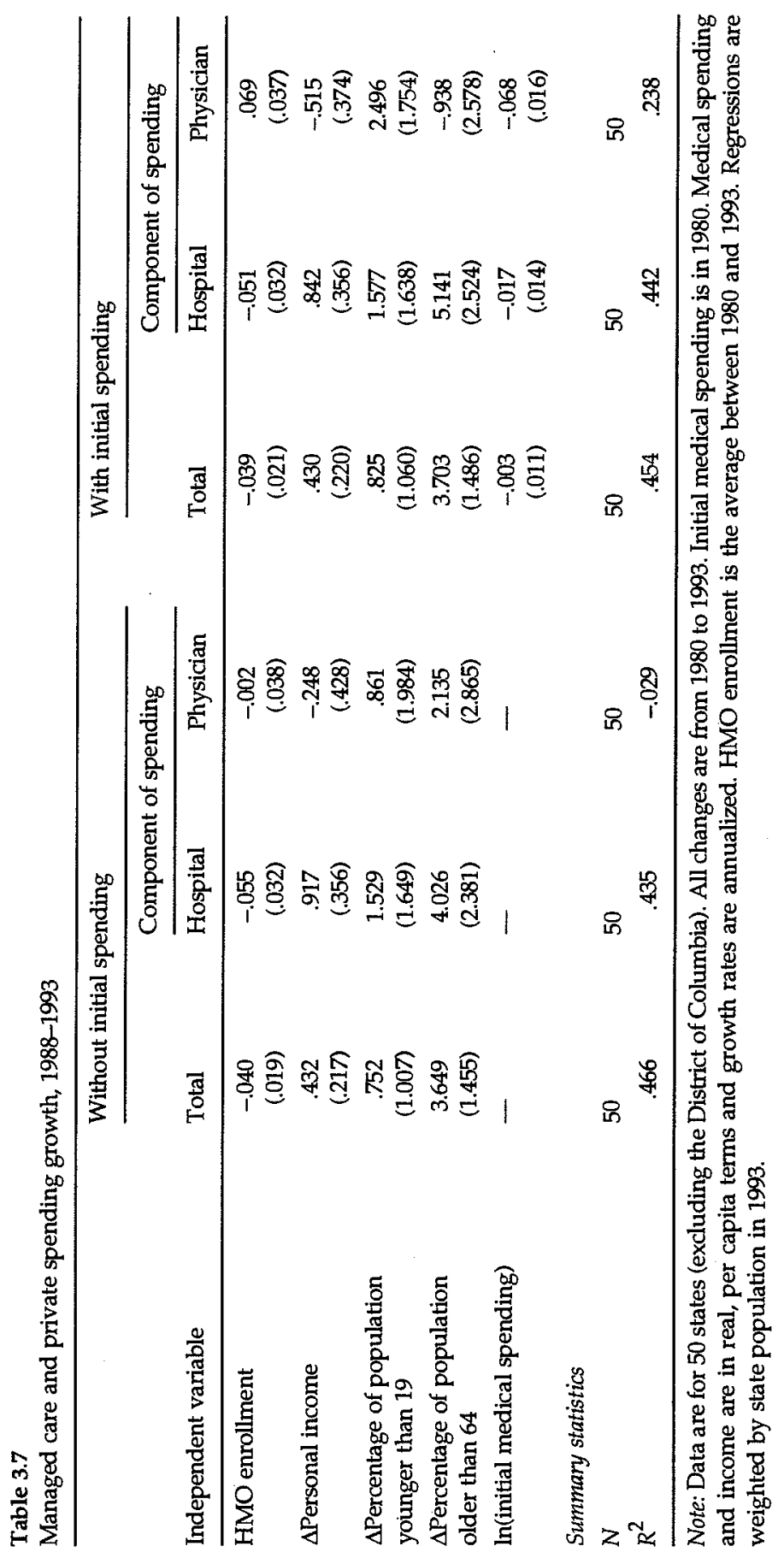




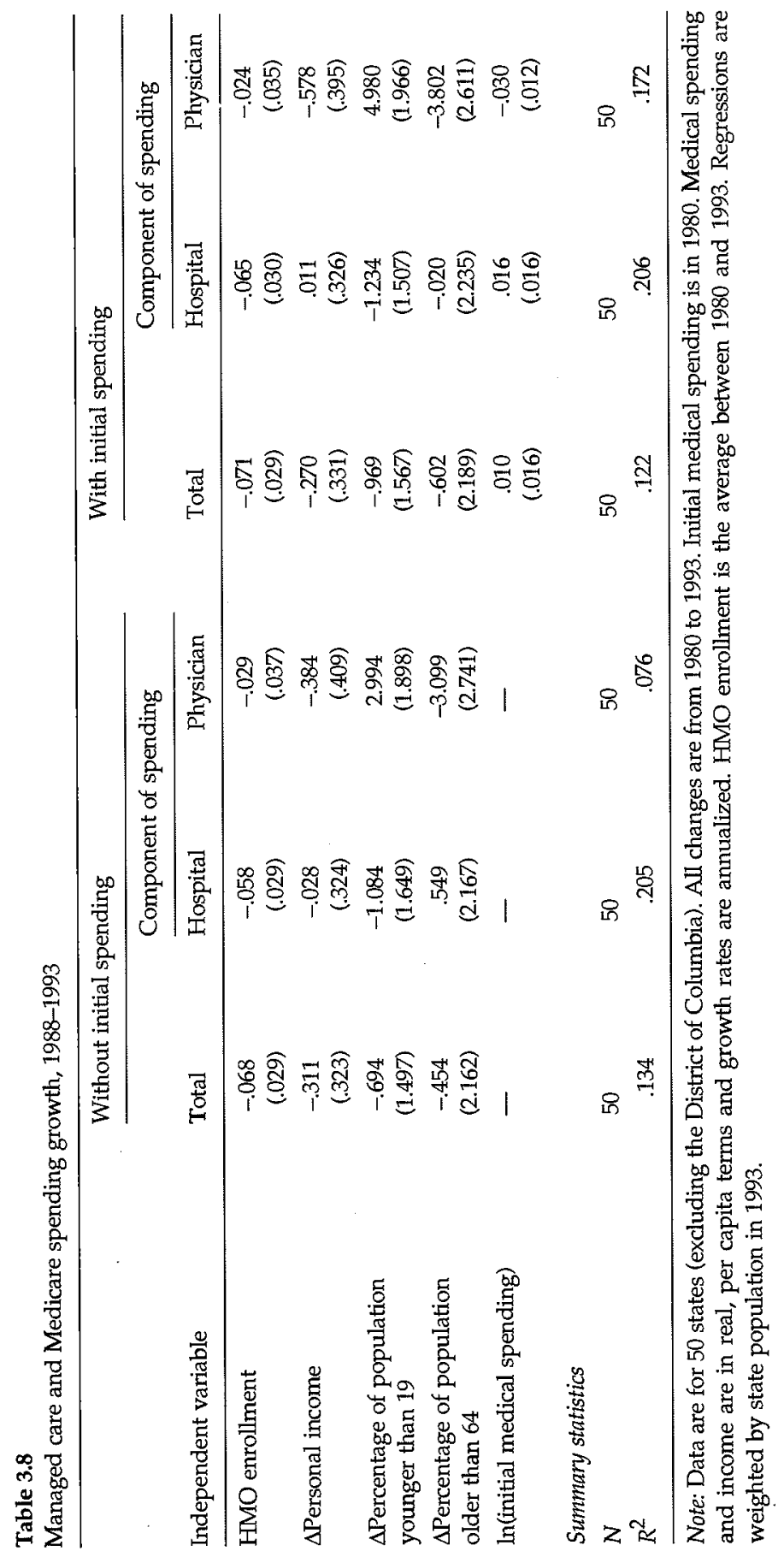


by about $0.4 \%$. These results are generally robust to a number of controls, including income, demographics, and the initial level of state spending.

\section{Explaining the Reduction in Hospital Costs}

To predict the longer-run effects of managed care, it is important to know not only whether managed care has affected medical spending, but how it has done so. Has managed care simply extracted rents from providers-reducing payments for procedures or cutting back at the margins? Or has there been a more significant change in the medical environment. In this section, we examine changes in hospital costs to address this issue.

We start with an accounting identity. Per capita spending on hospital care is the product of spending per day in the hospital times the average length of stay per admission times the number of hospital admissions per capita:

$$
\begin{aligned}
\left(\frac{\text { Spending }}{\text { Capita }}\right) & =\left(\frac{\text { Spending }}{\text { Admissions }}\right) \cdot\left(\frac{\text { Admissions }}{\text { Capita }}\right) \\
& =\left(\frac{\text { Spending }}{\text { Days }}\right) \cdot\left(\frac{\text { Days }}{\text { Admissions }}\right) \cdot\left(\frac{\text { Admissions }}{\text { Capita }}\right) .
\end{aligned}
$$

The growth of medical spending per capita can therefore be decomposed into the growth of each of these terms.

The first rows of table 3.9 show regression equations for the growth of hospital spending per adjusted admission and adjusted admissions per capita. ${ }^{13}$ Adjusted admissions are hospital admissions plus a factor to account for outpatient services provided, so that this figure approximates the total amount of hospital care provided. As the first row shows, HMOs have no significant effect on adjusted admissions per capita. The implication, shown in the second row, is that the entire decline in hospital growth associated with HMOs comes from a reduction in costs per admission. Decomposing this factor into days of care and costs per day (the next four rows) reveals that most of the reduction in the costs per admission comes from a reduction in the length of hospital stays. On average, a ten-percentage-point increase in the frac-

13. The coefficients shown in the table are those on the average HMO enrollment and those on the initial hospital spending, but the regressions also include the change in per capita income and the change in the population shares of old and young. 
Table 3.9

HMO enrollment and components of hospital spending

\begin{tabular}{|c|c|c|c|c|}
\hline \multirow[b]{2}{*}{ Change in } & \multicolumn{2}{|l|}{ 1980-1993 } & \multicolumn{2}{|l|}{ 1988-1993 } \\
\hline & $\begin{array}{l}\text { Average } \\
\text { HMO } \\
\text { enrollment }\end{array}$ & $\begin{array}{l}\text { Initial } \\
\text { hospital } \\
\text { spending }\end{array}$ & $\begin{array}{l}\text { Average } \\
\text { HMO } \\
\text { enrollment }\end{array}$ & $\begin{array}{l}\text { Initial } \\
\text { hospital } \\
\text { spending }\end{array}$ \\
\hline Adjusted admissions per person & $\begin{array}{l}.018 \\
(.013)\end{array}$ & $\begin{array}{l}.011 \\
(.004)\end{array}$ & $\begin{array}{l}.019 \\
(.017)\end{array}$ & $\begin{array}{c}.014 \\
(.006)\end{array}$ \\
\hline Cost per adjusted admission & $\begin{array}{l}-.065 \\
(.016)\end{array}$ & $\begin{array}{l}-.030 \\
(.005)\end{array}$ & $\begin{array}{l}-.093 \\
(.034)\end{array}$ & $\begin{array}{l}-.017 \\
(.013)\end{array}$ \\
\hline \multicolumn{5}{|l|}{ Length of stay per admission } \\
\hline All & $\begin{array}{c}-.053 \\
(.021)\end{array}$ & $\begin{array}{l}-.006 \\
(.007)\end{array}$ & $\begin{array}{l}-.080 \\
(.025)\end{array}$ & $\begin{array}{l}.006 \\
(.009)\end{array}$ \\
\hline Private & $\begin{array}{l}-.716 \\
(.378)\end{array}$ & $\begin{array}{l}-.084 \\
(.125)\end{array}$ & $\begin{array}{l}-.417 \\
(.178)\end{array}$ & $\begin{array}{l}.035 \\
(.067)\end{array}$ \\
\hline Medicare & $\begin{array}{l}-.551 \\
(.221)\end{array}$ & $\begin{array}{l}-.123 \\
(.073)\end{array}$ & $\begin{array}{l}-.283 \\
(.156)\end{array}$ & $\begin{array}{l}-.012 \\
(.058)\end{array}$ \\
\hline Costs per inpatient day & $\begin{array}{l}-.013 \\
(.022)\end{array}$ & $\begin{array}{l}-.023 \\
(.007)\end{array}$ & $\begin{array}{l}-.013 \\
(.027)\end{array}$ & $\begin{array}{l}-.021 \\
(.010)\end{array}$ \\
\hline Adjusted days per person & $\begin{array}{l}-.033 \\
(.022)\end{array}$ & $\begin{array}{l}.003 \\
(.007)\end{array}$ & $\begin{array}{l}-.061 \\
(.025)\end{array}$ & $\begin{array}{l}.018 \\
(.009)\end{array}$ \\
\hline Outpatient visits per person & $\begin{array}{l}-.053 \\
(.038)\end{array}$ & $\begin{array}{l}.029 \\
(.012)\end{array}$ & $\begin{array}{l}.026 \\
(.058)\end{array}$ & $\begin{array}{l}.077 \\
(.022)\end{array}$ \\
\hline $\begin{array}{l}\text { Full-time hospital employees } \\
\text { per person }\end{array}$ & $\begin{array}{l}-.060 \\
(.018)\end{array}$ & $\begin{array}{l}-.006 \\
(.006)\end{array}$ & $\begin{array}{l}-.056 \\
(.025)\end{array}$ & $\begin{array}{l}-.006 \\
(.010)\end{array}$ \\
\hline Hospital beds per person & $\begin{array}{l}-.045 \\
(.017)\end{array}$ & $\begin{array}{l}.003 \\
(.006)\end{array}$ & $\begin{array}{l}-.076 \\
(.028)\end{array}$ & $\begin{array}{l}.019 \\
(.010)\end{array}$ \\
\hline
\end{tabular}

Note: All regressions include change in real per capita income and changes in fraction of population younger than 20 and older than 64 . Data are for 50 states and are weighted by 1993 population. 
tion of the population enrolled in HMOs leads to lengths of stay declining 0.5 percentage points faster per year. HMOs have a negative but insignificant effect on the average cost per day in the hospital.

The finding that all of the cost savings are in shorter hospital stays may be somewhat misleading. Because the amount of care given to a patient likely declines with additional days in the hospital, one might have expected states that experienced a greater reduction in length of stay to have shown an increase in the average cost per day. When controlling for length of stay, HMO enrollment does reduce cost per day. ${ }^{14}$

Direct measures of hospital resource utilization also vary with managed care. On average, states with a large fraction of their populations enrolled in HMOs have slower growth of hospital employees per person and less bed growth per person.

The table's right columns show the results for 1988-93. HMOs have a slightly larger effect on costs per admission in this period relative to the whole time period, consistent with our earlier results. Also, total days in the hospital (including an adjustment for outpatient visits) have declined significantly more in states with high HMO enrollment, although again HMOs have not significantly affected the costs per inpatient day. Length of stay for Medicare beneficiaries in this postPPS adjustment period have also declined in states with high HMO enrollment, again indicating that changes in hospital practice styles have spillover effects.

\section{Changes in Technology Adoption}

We are particularly interested in the extent to which managed care has reduced the diffusion of medical technology, because that directly measures its long-run impact on cost growth. We thus examine this issue in some detail, using data on the adoption of specific technologies across states from the American Hospital Association's [AHA] annual survey, which asks whether hospitals have acquired a variety of important and expensive technologies. We analyze survey responses for

14. When the change in the length of stay is included in the regression, the effect of a ten-percentage-point increase in HMO enrollment is to reduce the growth of costs per day by 0.5 percentage points per year. Over 1988-93, however, the effect of HMO enrollment on costs per day is only about half this magnitude and is statistically insignificant. 
1980, 1985, 1990, and 1995 to look at how managed-care enrollment affects technology diffusion over time. ${ }^{15}$

Our ideal measure of technology diffusion is the rate at which particular technologies are used for patients with similar clinical conditions. The AHA does not ask about technology use, however, only whether the hospital owns the technology. We thus use as our measure of technology diffusion the number of units of each technology per million persons in the state. ${ }^{16}$ If all units perform roughly the same number of procedures, this accurately measures technology diffusion. If managed care consolidates technologies into some hospitals and keeps it out of other hospitals, however, we might find that managed care reduces technology's availability when in fact it does not reduce its actual utilization. Unfortunately, there is no way to surmount this issue without detailed information that we do not have on the use of particular procedures.

Table 3.10 shows the range of technologies we analyze, which are in five groups: cardiac technologies (catheterization lab, open-heart surgery facilities, and angioplasty facilities); radiation therapy (megavoltage radiation, radioactive implants, therapeutic radioisotope, $\mathrm{X}$-ray therapies, and stereotactic radiosurgery); diagnostic radiology (CT scanner, diagnostic radioisotope, MRI, ultrasound, positron emission tomography [PET], and single photon emission computed tomography [SPECT]); transplantation services (kidney, organ [other than kidney], tissue, bone marrow); and other (extracorporeal shock wave lithotripter).

Perhaps more important than their grouping by service, however, our data are a mix of diffusing technologies and technologies that have already diffused. Catheterization labs, for example, go from four per million in 1980 to seven per million by 1995; CT scanners go from five per million in 1980 to twenty per million in 1995. Other technologies, such as radioactive implants and ultrasound machines, had already diffused by this time period. We classify the technologies that are diffusing over our time period into one group (the diffusing sample):

15. If a hospital does not respond to the AHA survey in some year, it has missing data about technologies. We use data on the previous four years of responses to impute technology ownership, where possible.

16. An alternative measure of technology availability would be the share of hospitals with a particular technology. This would be particularly sensitive to changes in the number of hospitals, however, which our earlier results suggest managed care affects. We thus do not use this measure. 
Table 3.10

Diffusion of medical technologies

\begin{tabular}{|c|c|c|c|c|}
\hline \multirow[b]{2}{*}{ Technology } & \multicolumn{4}{|c|}{ Units per million people } \\
\hline & 1980 & 1985 & 1990 & 1995 \\
\hline \multicolumn{5}{|l|}{ Cardiac } \\
\hline Catheterization & 4.1 & 4.6 & 6.2 & 6.8 \\
\hline Open-heart surgery & 2.7 & 3.0 & 3.7 & 4.0 \\
\hline Angioplasty & - & - & 4.6 & 4.7 \\
\hline Radiation therapy & - & - & - & 5.0 \\
\hline Megavoltage radiation & 3.8 & 4.1 & 4.2 & - \\
\hline Radioactive implants & 5.9 & 5.9 & 5.1 & - \\
\hline Therapeutic radioisotope & 6.8 & 6.1 & 5.6 & - \\
\hline$X$-ray therapy & 5.5 & 4.4 & 4.0 & - \\
\hline Stereotactic radiosurgery & - & - & 1.1 & - \\
\hline \multicolumn{5}{|l|}{ Diagnostic radiology } \\
\hline CT scanner & 5.2 & 13.3 & 17.7 & 19.7 \\
\hline Diagnostic radioisotope & 18.7 & 17.0 & 16.0 & 14.0 \\
\hline MRI & - & 1.2 & 4.3 & 9.5 \\
\hline Ultrasound & 一 & 21.4 & 24.6 & 23.3 \\
\hline PET scanner & - & - & 0.4 & 0.6 \\
\hline SPECT scanner & - & - & 4.2 & 7.2 \\
\hline Transplant services & - & - & - & 2.0 \\
\hline Kidney transplant & 0.7 & 0.8 & 0.9 & - \\
\hline Other organ transplant & 1.0 & 1.1 & 1.1 & - \\
\hline Tissue transplant & - & - & 1.2 & - \\
\hline Bone marrow transplant & 一 & - & 0.7 & - \\
\hline Lithotripter & - & 0.2 & 1.4 & 3.1 \\
\hline
\end{tabular}

Note: Data on ownership are from the American Hospital Association Annual Survey. The maximum number of units per million is 31.4 in 1980, 29.5 in 1985, 27.3 in 1990, and 24.5 in 1995. 
catheterization, open-heart surgery, angioplasty, megavoltage radiation, stereotactic radiosurgery, CT scanners, MRIs, PET scanners, SPECT scanners, transplant services, and lithotripters. The other technologies (radioactive implants, therapeutic radioisotopes, $\mathrm{X}$-ray therapy, and diagnostic radioisotopes) we classify as already diffused.

In addition to the distinction between diffusing and already-diffused technologies, we also have variation within the diffusing technologies in time of introduction. For example, angioplasty was about as diffused in 1990 as cardiac catheterization was in 1980; SPECT scanners in 1990 were about as diffused as CT scanners in 1980. Thus, we can look at how managed care has changed over time the diffusion of technologies in the same state of overall diffusion.

To examine the relation between managed-care enrollment and technology adoption in 1980, we estimate models similar to our previous analysis:

$\left(\frac{\text { Units }}{\text { Million }}\right)_{s}=\beta_{1} H$ MO Enrollment En $_{s}+X_{s} \beta+\varepsilon_{s}$,

where $s$ indexes states. As control variables $(\mathrm{X})$, we include the logarithm of per capita income in the state, the percentage of the population living in urban areas, and the logarithm of state population. ${ }^{17}$ As before, all regressions are weighted by state population.

The first column of table 3.11 shows estimates of equation (3.3). We report only the coefficient on the HMO enrollment variable. In general, the other variables are as we would expect: States with higher incomes have increased technology diffusion, and more-urban areas have less technology diffusion (reflecting shorter commuting times). As population increases, so does the number of units of technology per million.

The table's first row shows that for all of the technologies, HMO enrollment has a positive but statistically insignificant effect on technology diffusion. Each ten-percentage-point increase in HMO enrollment raises the ownership of the average technology by 0.2 units per million people. The next two rows show that this effect is very different for the diffusing technologies relative to those already diffused. Among the diffusing technologies, HMO enrollment is associated with more technology ownership. The coefficient is positive and statistically significant. Among already diffused technologies, in contrast, HMO

17. We experimented with other population characteristics but found they were not significantly related to technology ownership. 


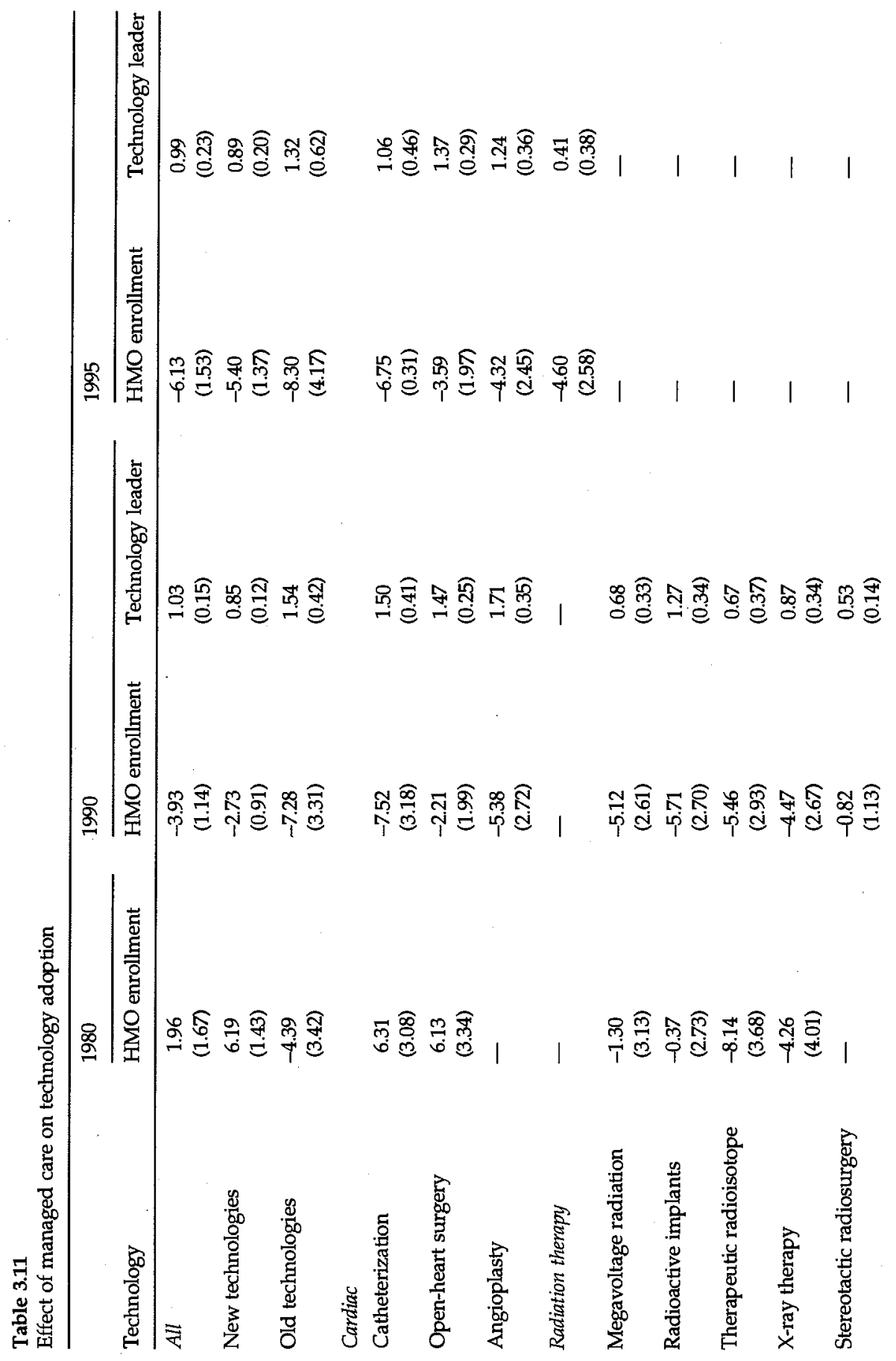




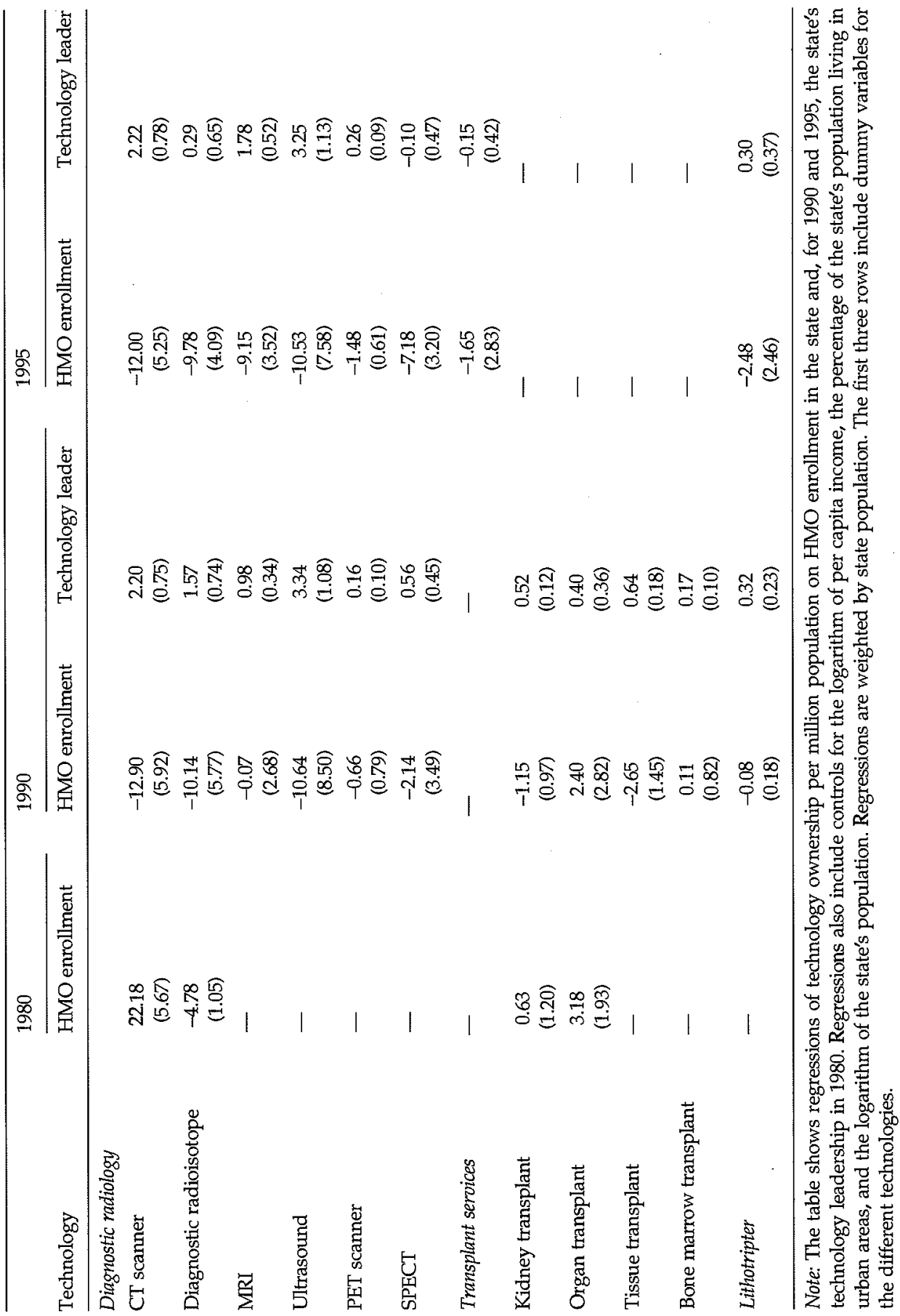




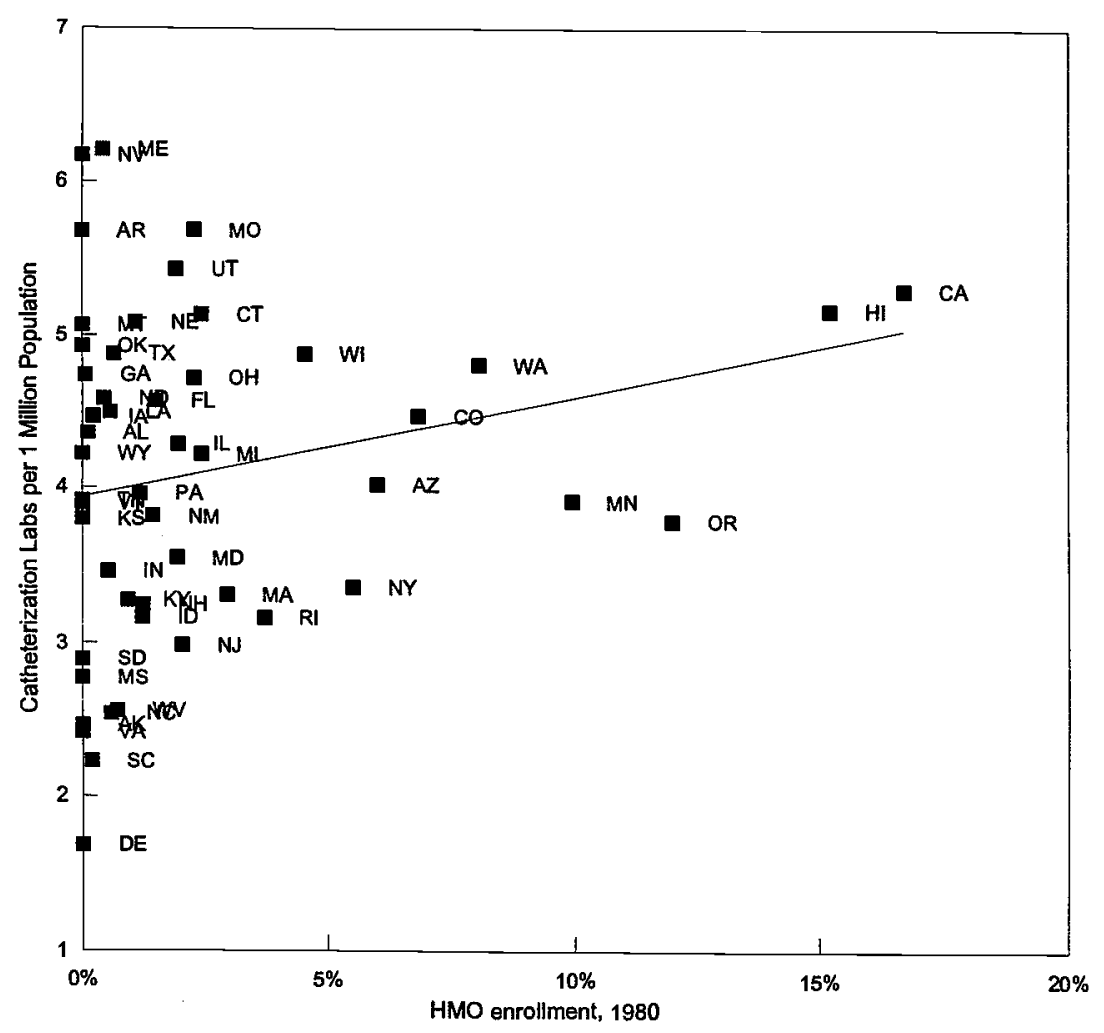

Figure 3.9

HMO enrollment and the diffusion of cardiac catheterization labs, 1980

enrollment has an insignificant negative effect on the ownership of technology.

The insignificant effect of HMOs on already-diffused technologies suggests that HMO enrollment is not associated with long-run differences in technology availability across states. This makes sense; technologies available for some time have spread more or less equally among all states. But states with high HMO enrollment in 1980 are technology leaders-new technologies are more common there than in other states.

Figure 3.9 shows this graphically by depicting the relation between HMO enrollment and cardiac catheterization units in 1980. States like California and Hawaii, leaders in managed-care enrollment, also have high numbers of catheterization units. HMO enrollment is positively correlated with catheterization labs. 
We want to know how the HMO coefficient changes over time. If managed care is reducing the diffusion of new technologies, the HMO coefficient should fall in the later years of the sample. There is a problem, however, in simply estimating equation (3.3) for different years. Our results for 1980 suggest that some states are naturally technology leaders and others are technology "followers." If we want to look at managed care's effect on technology diffusion, we need to control for whether the state is a technology leader. ${ }^{18}$ That is, we need to modify equation (3.3) to:

$$
\left(\frac{\text { Units }}{\text { Million }}\right)_{s}=\beta_{1} \text { HMO Enrollment }{ }_{s}+\beta_{2} \text { Technology Leader }_{s}+x_{s} \beta+\varepsilon_{s} \text {. }
$$

Here, $\beta_{1}$ gives HMO enrollment's effect on technological availability, controlling for the fact that some states are naturally leaders and others are followers.

There is clearly no variable for technology leadership. But our data suggest a natural proxy: We take all of the diffusing technologies in 1980 and normalize the ownership variables so that they have a mean of zero and a standard deviation of one. ${ }^{19} \mathrm{We}$ then add the normalized ownership measures across the different technologies. The result is a measure of the state's propensity to own high-tech medical services in 1980, which we use as a proxy for technology leadership.

The second through fifth columns of table 3.11 show estimates of equation (3.4) in 1990 and 1995. We report only the coefficients on HMO enrollment and the technology leadership variable, although the logarithm of per capita income, the share of the state living in urban areas, and the logarithm of state population are also included in the regression.

Increased HMO enrollment is associated with less-rapid diffusion of new technologies in 1990 and 1995, and this effect is increasing over time. As the first row shows, states that were technology leaders in 1980 are more likely to adopt new technologies in the 1990s. The coefficient on the leadership variable is positive and statistically

18. In examining the managed care's impact on technology adoption, Chernew, Fendrick, and Hirth (1997) examined whether a new gallbladder surgery, laparoscopic cholecystectomy, diffused more slowly within HMOs. They found little difference between HMOs and the general population in the rate of growth in utilization. However, they were not able to control for this "leader effect," which might have led to their results.

19. That is, we form $z_{s}=($ units/million s $-\mu) / \sigma$, where $\mu$ is the mean ownership across states and $\sigma$ is the standard deviation. 


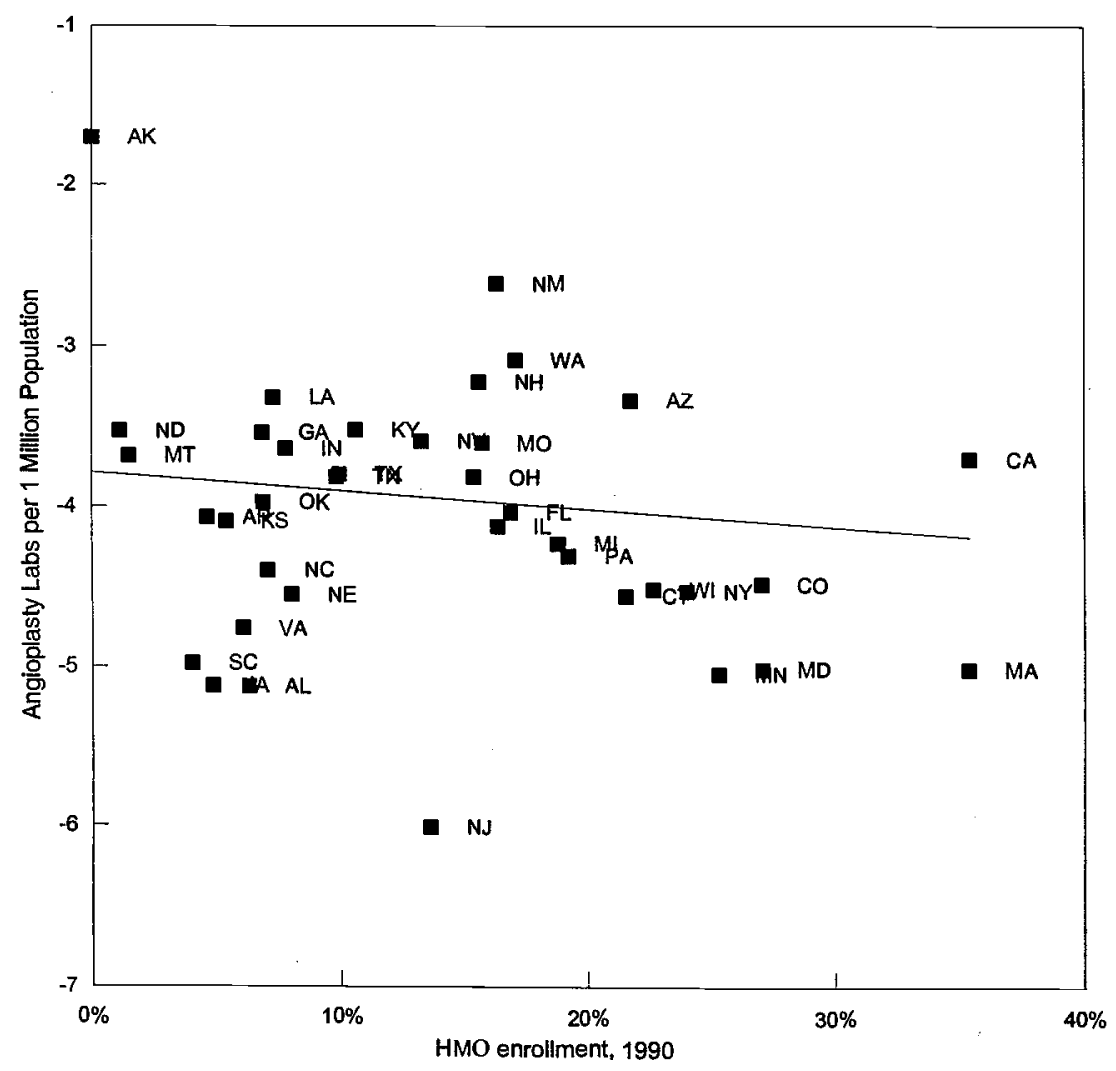

Figure 3.10

HMO enrollment and the diffusion of angioplasty labs, 1990

significant. Conditional on this effect, however, increased HMO enrollment significantly reduces the propensity of states to adopt new technologies. Further, the coefficient on HMO enrollment is more negative in 1995 than in 1990, suggesting that HMO enrollment is increasingly affecting the diffusion of new technologies over time. This finding is not just a result of the fact that technologies are on average older in the 1990s than in 1980. Even for the new technologies of the late 1980s and early 1990s, such as angioplasty, PET scanners, SPECT scanners, and lithotripters, the coefficients on HMO enrollment are generally negative and often statistically significant.

Figure 3.10 shows one particular example graphically by depicting the relation between HMO enrollment in 1990 and the number of angioplasty units per million people. Angioplasty in 1990 is roughly 
the technological equivalent to cardiac catheterization in 1980; both are procedures used in the treatment of severe coronary problems. Thus, the comparison between figures 3.9 and 3.10 implicitly reveals HMOs' effect on similar technologies over time. As figure 3.10 shows, there is essentially no relation between $\mathrm{HMO}$ enrollment and angioplasty units. Even though the high managed-care states in 1980 are generally the high managed-care states in 1990, those states are not the ones where technology is diffusing most rapidly. California, for example, is only average in angioplasty units, and Massachusetts, another high HMO state, is below average. When we control for the fact that these states were technology leaders in 1980, our regressions in table 3.11 indicate a negative and statistically significant effect of managed care on technology diffusion.

In principle, managed care might affect different types of technologies differently. Technologies that save money might be adopted more readily in heavy managed-care states, whereas technologies that add to costs should diffuse less rapidly. We find it difficult to analyze this in our data, however; a more systematic study of this issue would be needed to reach firm conclusions.

\section{Conclusion}

The differences across states in the pervasiveness of managed care has allowed us to examine managed care's effects on health care systemslooking not only at the insurance premiums those in managed care pay or the reimbursement providers receive from managed-care companies but at managed care's total impact on health expenditures. The results are fairly encouraging. ${ }^{20}$ The higher is $\mathrm{HMO}$ enrollment in a state, the lower is the growth of hospital spending. Over the entire 1980-93 period, an equal increase in physician and drug spending almost negated the reduction in hospital cost growth. However, in 1988-93, the increase in physician spending was much more muted, and managed care reduced the growth rate not only of hospital spending, but of spending overall.

Managed care's impact on physician spending was a surprise to us, and it warrants further investigation. Its impact on hospitals was more in line with anecdotal evidence-managed care reduced hospital costs

20. Of course, without a measure of health outcomes, it is impossible to determine whether managed care is worth its cost. 
primarily by reducing the length of stay in the hospital, leading to fewer hospital employees per person as well as fewer hospital beds.

Perhaps more important than the finding that managed care reduces health spending overall is the preliminary evidence that managed care may also slow the rate of adoption of new technologies. States with high enrollment in HMOs used to be the first to adopt new technologies; now, they are only average. Because rapid adoption of new technology is believed to be one of the main factors behind the rise in health expenditures, the finding that HMOs can reduce technology adoption means that managed care may actually moderate the longterm growth of health expenditures. That is a subject well worth further investigation.

\section{References}

Aaron, Henry. 1991. Serious and Unstable Condition: Financing America's Health Care. Washington, DC: The Brookings Institution.

Baker, Lawrence C. 1997. "The Effect of HMOs on Fee-for-Service Health Care Expenditures: Evidence from Medicare." Journal of Health Economics 16(4):453-481.

Chernew, Michael, A. Mark Fendrick, and Richard A. Hirth. 1997. "Managed Care and Medical Technology: Implications for Cost Growth." Health Affairs 16(2) (March/April):196-206.

Cutler, David M., and Mark McClellan. 1996. "The Determinants of Technological Change in Heart Attack Treatments." NBER Working Paper No. 5751, September 1996.

Gabel, Jon. 1997. "Ten Ways HMOs Have Changed during the 1990s." Health Affairs 16(3) (May/June):134-45.

Gabel, Jon, Cindy Jajich-Toth, Gregory de Lissovoy, Thomas Rice, and Howard Cohen. 1988. "The Changing World of Group Health Insurance." Health Affairs 7(3) (summer):4865.

Holahan, John, and David Liska. 1997. "The Slowdown in Medicaid Spending Growth: Will It Continue?" Health Affairs 16(2) (March/April):157-63.

Jensen, Gail A., et al., 1997. "The New Dominance of Managed Care Insurance: Trends in the 1990s." Health Affairs 16(1) (January/February):148-156.

Krueger, Alan B., and Helen Levy. 1997. "Accounting for the Slowdown in Employer Health Care Costs." "National Tax Association Proceedings," 61-75.

Levit, Katharine R., Helen C. Lazenby, Cathy A. Cowan, Darleen K. Won, Jean M. Stiller, Lekha Sivarajan, and Madie W. Stewart. 1995. "State Health Expenditure Accounts: Building Blocks for State Health Spending Analysis." Health Care Financing Review 17(1) (fall)201-54.

Melnick, Glenn, and Jack Zwanziger. 1995. "State Health Care Expenditures under Competition and Regulation, 1980 through 1991." American Journal of Public Health 85(10) (October):1391-6. 
Newhouse, Joseph P. 1992. "Medical Care Costs: How Much Welfare Loss?" Journal of Economic Perspectives, 6(3) (Summer):3-21.

Newhouse, Joseph P., and the Insurance Experiment Group. 1993. Free For All? Lessons from the Rand Health Insurance Experiment. Cambridge, MA: Harvard University Press.

Reinhardt, Uwe. 1996. "Our Obsessive Quest to Gut the Hospital." Health Affairs 15(3) (summer):145-54.

Simon, Carol, and Patricia Born. 1996. "Physician Earnings in a Changing Managed Care Environment." Health Affairs 15(4) (fall):124-33.

Simon, Carol, and David W. Emmons. 1997. "Physician Earnings at Risk: An Examination of Capitated Contracts." Health Affairs 16(3) (May/June):134-45.

Wholey, Douglas, Roger Feldman, and Jon Christianson. 1995. "The Effect of Market Structure on HMO Premiums." Journal of Health Economics 14(1):81-105.

Wickizer, Thomas M., and Paul J. Feldstein, 1995. "The Impact of HMO Competition on Private Health Insurance, 1985-1992." Inquiry 32(3):241-252.

Zwanziger, Jack, and Glenn Melnick. 1996. "Can Managed Care Plans Control Health Care Costs?" Health Affairs 15(3) (summer):185-99. 
